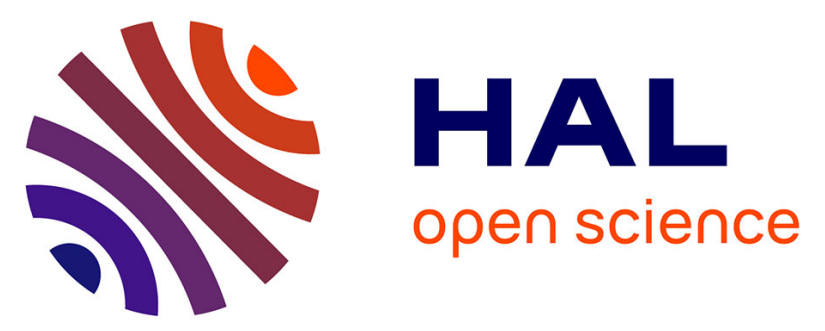

\title{
Heterosynaptic metaplastic regulation of synaptic efficacy in CA1 pyramidal neurons of rat hippocampus
}

Didier Le Ray, David Fernández de Sevilla, Ana Belén Porto, Marco Fuenzalida, Washington Buño

\section{- To cite this version:}

Didier Le Ray, David Fernández de Sevilla, Ana Belén Porto, Marco Fuenzalida, Washington Buño. Heterosynaptic metaplastic regulation of synaptic efficacy in CA1 pyramidal neurons of rat hippocampus. Hippocampus, 2004, 14 (8), pp.1011-1025. 10.1002/hipo.20021 . hal-02347061

\author{
HAL Id: hal-02347061 \\ https://hal.science/hal-02347061
}

Submitted on 7 Nov 2019

HAL is a multi-disciplinary open access archive for the deposit and dissemination of scientific research documents, whether they are published or not. The documents may come from teaching and research institutions in France or abroad, or from public or private research centers.
L'archive ouverte pluridisciplinaire HAL, est destinée au dépôt et à la diffusion de documents scientifiques de niveau recherche, publiés ou non, émanant des établissements d'enseignement et de recherche français ou étrangers, des laboratoires publics ou privés. 


\title{
HETEROSYNATIC METAPLASTIC REGULATION OF SYNAPTIC EFFICACY IN CA1 PYRAMIDAL NEURONS OF RAT HIPPOCAMPUS
}

\author{
Didier LE RAY ${ }^{1}$, David FERNÁNDEZ DE SEVILLA, Ana Belén PORTO², Marco \\ FUENZALIDA and Washington BUÑO
}

INSTITUTO CAJAL, CSIC, AV. DR ARCE 37, 28002 MADRID, SPAIN

CURRENT ADDRESSES: ${ }^{1}$ CNRS-UMR 5543, Université Victor Ségalen, Bordeaux, France.

${ }^{2}$ Laboratorio RNASA, Departamento de Tecnologías de la Información y las Comunicaciones, Universidade da Coruña, Spain.

RUNNING TITLE: Heterosynaptic metaplasticity

TEXT PAGES: 31. FIGURES: 5. TABLES: 0.

CORRESPONDENCE TO: Washington Buño, Instituto Cajal, CSIC, Av. Dr. Arce 37, 28002 Madrid, Spain. Phones: 34-91-5854711 // 34-91-5854712. Fax: 34-91-5854754. E-mail: wbuno@cajal.csic.es

Supported by grants to Washington Buño from: (i) Dirección General de Investigación Científica y Tecnológica, Ministerio de Educación y Cultura (Spain); Number: PM980113; (ii) Ministerio de Ciencia y Tecnología (Spain); Number: BFI2002-0110.

Other finantial supports were to:

Didier Le Ray: Postdoctoral Fellow: Sponsor: Human Frontier Science Program Organization; Numbers: LT0647/1998-B and ST00072/2001-C.

David Fernández de Sevilla: Postdoctoral Contract: Sponsor: Ministerio de Educación y Cultura and Ministerio de Ciencia y Tecnología (Spain).

Ana Belén Porto: Fellowship “Iniciación a la Investigación”: Sponsor: Consejo Superior de Investigación Científicas (Spain).

Marco Fuenzalida: Doctoral Fellow: Sponsor: Ministerio de Relaciones Exteriores - Agencia de Cooperación Internacional (Spain).

KEYWORDS: slow after hyperpolarization; LTP; $\mathrm{sI}_{\mathrm{AHP}}$ channels; $\mathrm{Ca}^{2+}$ dynamics; simulation 


\section{ABSTRACT}

The induction threshold, and the magnitude and direction of changes in synaptic plasticity may depend on the previous history of neuronal activity. This phenomenon termed “metaplasticity" could play an important role in integration processes by coordinating the modulation of synapses. Although metaplasticity has been extensively analyzed, its underlying cellular mechanisms remain largely unknown. Using in vitro electrophysiological and computer simulation approaches, we investigated the contribution of the slow $\mathrm{Ca}^{2+}$ dependent after-hyperpolarization (SAHP) in the metaplastic control of the induction of long-term potentiation (LTP) at convergent CA3-CA1 pyramidal neuron synapses. We report that classical conditioning protocols may lead to the simultaneous induction of a sustained homosynaptic LTP and a potentiation of the SAHP that endured $\approx 1 \mathrm{~h}$. The sAHP potentiation dramatically altered the spike responses of the CA1 pyramidal neuron. Of particular interest was the reduction of the CA1 neuron excitability and, consequently, of the capacity of a non-potentiated synaptic input to elicit spikes while the SAHP was potentiated. This reduction in excitability temporarily prevented non-potentiated synaptic inputs to exhibit an LTP induced by presynaptic tetanization. This metaplasticity was strongly resistant to increases in the magnitude of synaptic tetanization protocols. We propose that this heterosynaptic metaplasticity, mediated by intrinsic cellular mechanisms, triggered by brief periods of activity and relying on changes of a slow $\mathrm{Ca}^{2+}$-activated $\mathrm{K}^{+}$-current may contribute to adjust the efficacy of synaptic connections and shape network behavior to regulate integration processes. 


\section{INTRODUCTION}

In the vertebrate central nervous system brief periods of patterned activity can either potentiate or depress synaptic efficacy, the induction of which narrowly depends on the history of synaptic activity. This latter relationship is referred to as "metaplasticity" (Abraham and Bear, 1996). Data on metaplasticity have been mainly gathered from studies of glutamatergic synaptic plasticity (e.g., Huang et al., 1992; Bortoloto and Collingridge, 2000; Goussakov et al., 2000), and it is recognized that metaplasticity is induced by the same events that trigger synaptic plasticity (see Tompa and Friedrich, 1998). However, the cellular mechanisms underlying metaplasticity remain largely unknown.

According to Hebb’s postulate, a temporal association between pre- and postsynaptic spike activity is required to induce the synaptic changes that underlie information storage (Hebb, 1949). Action potentials back-propagating within the dendrites play a pivotal role in this scheme, providing the signal of postsynaptic activity required to induce long-term potentiation (LTP) (e.g., Magee and Johnston, 1997; Markram et al., 1997; Linden, 1999; Pike et al., 1999), a long-lasting enhancement in synaptic efficacy regarded as the neural basis for learning and memory. Understanding how modifications of synaptic efficacy translate into spikes and how changes in postsynaptic properties contribute to plasticity is essential to gain insights into the processes that regulate long-term plasticity and information storage (e.g., Bliss and Lomo, 1973; Armano et al., 2000; Daoudal et al., 2002; Wang et al., 2003; for recent reviews see Daoudal and Debanne, 2003; Zhang and Linden, 2003). Whether a neuron fires a spike or not depends both on synaptic input and intrinsic cellular properties. Therefore, to comprehend the cellular mechanisms by which metaplasticity regulates long-term plasticity it is necessary to determine both the changes in synaptic strength and postsynaptic excitability.

Recent studies suggest a role of the slow after-hyperpolarization (sAHP) in the modulation of cellular excitability and synaptic plasticity (e.g., Coulter et al., 1989; Cohen et al., 1999; Martin et al., 2001; Pedarzani et al., 2001; Carrer et al., 2003; Oh et al., 2003; for recent reviews see Wu 
et al., 2002; Daoudal and Debanne, 2003; Zhang and Linden, 2003). In CA1 neurons, the $\mathrm{Ca}^{2+}$ activated $\mathrm{K}^{+}$channels that underlie the sAHP (Storm, 1990) are mainly localized proximally in apical dendrites and may regulate the back-propagation of spikes (e.g., Sah and Bekkers, 1996; Johnston et al., 2000). Interestingly, work from our group demonstrated that the sAHP in CA1 pyramidal cells might undergo transient facilitation and modulate synaptic efficacy (Borde et al., 1995, 1999, 2000). In addition, it has been recently shown that both facilitation and depression of the sAHP may be induced by tetanic and theta burst stimulation with injected current, respectively (Kaczorowski et al., 2003). Therefore, by up- and down-regulating neuronal excitability the depression or potentiation of the sAHP may elevate or reduce, respectively, the induction threshold of the LTP.

We describe a novel cellular mechanism of metaplasticity, by which classical presynaptic conditioning protocols may lead to the simultaneous induction of a homosynaptic LTP and a shorter potentiation of the $\mathrm{Ca}^{2+}$-activated sAHP at the postsynaptic neuron. This synaptically induced enhancement of the sAHP alters the firing properties of the postsynaptic CA1 pyramidal neuron by increasing spike frequency adaptation and decreasing excitability and, thereby, prevents the induction of LTP at other, non-potentiated synapses. This cellular mechanism of heterosynaptic metaplasticity, triggered by brief periods of synaptic activity, relies on modifications of an intrinsic property that may control integration processes at the cellular level.

\section{MATERIALS AND METHODS}

Procedures of animal care, surgery, and slice preparation were in accordance with the guidelines laid down by the European Communities Council. These procedures will be described briefly because they have been extensively detailed previously (e.g., Borde et al., 1995; 2000).

Slice preparation. Young Wistar rats (14 to 16 days old) were anaesthetized with ether, decapitated, and the brain was removed and submerged in cold artificial cerebrospinal fluid (ACSF, in mM: $124.00 \mathrm{NaCl}, 2.69 \mathrm{KCl}, 1.25 \mathrm{KH}_{2} \mathrm{PO}_{4}, 2.00 \mathrm{Mg}_{2} \mathrm{SO}_{4}, 26.00 \mathrm{NaHCO}_{3}, 2.00 \mathrm{CACl}_{2}$, 
10.00 glucose). The $\mathrm{pH}$ of the ACSF was stabilized at 7.4 by bubbling carbogen $\left(95 \% \mathrm{O}_{2}\right.$, $5 \%$ $\left.\mathrm{CO}_{2}\right)$, and the temperature maintained at $4^{\circ} \mathrm{C}$. Transverse hippocampal slices $(300-350 \mu \mathrm{m})$ were cut with a Vibratome (Pelco 101, St Louis, MO) and incubated in the ACSF (1 hour, at 20-22 ${ }^{\circ}$ C). Slices were transferred to a $2 \mathrm{ml}$ chamber fixed to an inverted microscope stage (Nikon DiaphotTMD, Tokyo, Japan) or on a upright microscope equipped with water immersion objectives and infra red contrast interference optics and superfused with carbogen-bubbled ACSF (2 ml/min) either maintained at room temperature $\left(20-22^{\circ} \mathrm{C}\right)$ or at $32-34^{\circ} \mathrm{C}$ (no clear differences in the results were found when temperature was raised to $32-34^{\circ} \mathrm{C}$ ). In order to prevent any possible alteration by inhibitory plastic properties (e.g., Chapman et al., 1998; Chevaleyre and Castillo, 2003) $50 \mu \mathrm{M}$ picrotoxin was added to the ACSF to eliminate $\mathrm{GABA}_{\mathrm{A}}$ inhibition. Nevertheless, sAHP potentiation was also observed in a few control experiments (5/7) performed in normal ACSF.

Recordings, stimulation, and analysis. Two recording techniques were used: (i) whole-cell patch-clamp recordings using 4-8 $\mathrm{M} \Omega$ glass pipettes filled with a $\mathrm{KMeSO}_{4}(150 \mathrm{mM}) / \mathrm{ATP}$ (2 mM) / GTP (10 mM) solution (Zhang et al., 1994), pH was adjusted to 7.2 with $\mathrm{KOH}$; and (ii) intracellular recordings with 80-100 M $\Omega$ K-acetate (3 M)-filled sharp micropipettes. Patch pipettes or sharp electrodes were connected to an Axoclamp 2B amplifier (Axon Instruments, Inc., Foster City, CA), and recording was either in the single-electrode voltage-clamp or current-clamp bridge modes. Recordings with patch pipettes in the voltage-clamp configuration aimed at reducing the possible contamination by voltage-sensitive conductances that could occur in current-clamp recordings of Schaffer collateral (SC)-evoked synaptic responses and the $\mathrm{K}^{+}$current that mediates the sAHP ( $\left.\mathrm{sI}_{\mathrm{AHP}}\right)$. However, because the prolonged intracellular dialysis associated with wholecell recordings may prevent the induction of synaptic plasticity sharp electrodes were used for studies of metaplastic events which required conditioning stimulation alternately of two separate SC inputs during long duration experiments. Patch or sharp pipettes were placed under direct visualization of the CA1 soma layer (Fig. 1A), the typical pyramidal neuron morphology, and the presence of spike frequency accommodation, sag and post-inhibitory rebound in response to 
intracellular current steps identified the pyramidal neurons (e.g., Schwartzkroin, 1975; Borde et al., 1995).

Recordings started 5 min after access to the intracellular compartment in the whole-cell configuration, and 20 min after cell penetration with the sharp electrode, in order to allow a period for complete stabilization of the recorded neurons. In the whole-cell voltage-clamp configuration, neurons were accepted only when seal resistance was $>1 \mathrm{G} \Omega$ and series resistance changed by $\leq 5$ \% during the experiment. Sharp electrode current-clamp recordings were rejected if the resting membrane potential (Vr) depolarized above $-50 \mathrm{mV}$. Neurons were voltage-clamped at a holding potential of $-50 \mathrm{mV}$ and the $\mathrm{sI}_{\mathrm{AHP}}$ was induced by applying a $200 \mathrm{~ms}$ voltage step to $0 \mathrm{mV}$, which allowed a massive $\mathrm{Ca}^{2+}$ entry within the cell (e.g., Martín et al., 2001; Carrer et al., 2003). In the current-clamp configuration, recordings were performed at the $\mathrm{Vr}$, except when otherwise indicated, and the sAHP was elicited by a high intensity 200 ms intracellular depolarizing current pulse that evoked a high rate spike burst.

Experiments were also performed under block of $N$-methyl- $D$-aspartate (NMDA) type glutamate receptors with D-2-amino-5-phosphonopentanoic acid (AP-5; $50 \mu \mathrm{M}$ ) and inhibition of L-type voltage-activated $\mathrm{Ca}^{2+}$ channels with nimodipine $(20 \mu \mathrm{M})$. Drugs were purchased from Sigma (St. Louis, MO), except $\mathrm{KMeSO}_{4}$, AP-5 and nimodipine that were from IBN Biomed Inc. (Aurora, $\mathrm{OH}$ ).

Afferent SC stimulation (Grass S88 and SIU, Quincy, MA, USA) was performed using thin bipolar Nickel-Chrome electrodes ( $80 \mu \mathrm{m}$ diameter) placed at the stratum radiatum near the CA2 region ( $<500 \mu \mathrm{m}$ from somatic layer). Except during conditioning protocols (see below), afferent stimulation was applied at $0.2 \mathrm{~Hz}$, and the intensity was set such that every single stimulation produced a depolarizing postsynaptic response (EPSP/EPSC) but no action potential in the recorded CA1 pyramidal neuron. When two convergent presynaptic SC pathways (i.e., SC1 and 
SC2) were stimulated, electrodes were separated by $\sim 200 \mu \mathrm{m}$ (Fig. 1A), and paired pulse presynaptic facilitation tests established that two distinct groups of afferents were stimulated.

Several stimulation protocols were used to induce both synaptic LTP and $\mathrm{sI}_{\mathrm{AHP}}$ potentiation: (i) tetanization by ten $200 \mathrm{~ms} / 50-100 \mathrm{~Hz}$ barrages repeated at $2 \mathrm{~Hz}$ (e.g., Fig. 2A); (ii) $1-2 \mathrm{~Hz}$ presynaptic stimulation with single pulses coupled with the injection of a continuous depolarizing current within the postsynaptic CA1 cell and applied during 120 s (LFSD; e.g., Fig. 2C); or (iii) theta-burst stimulation that consisted of five to ten sequences of four pulses at $100-\mathrm{Hz}$ repeated at 5 Hz, and applied every 5 s (TBS; e.g., Fig. 2D). During tetanization and TBS protocols the CA1 pyramidal neuron was slightly depolarized by injection of continuous current so that every single EPSP evoked one action potential. The cell was returned to the control membrane potential after the induction protocol had been applied. In patch-clamp experiments, stimulation protocols to evoke LTP were presented within the first 20 min after access to the intracellular compartment in order to reduce the effects of intracellular dialysis. In current clamp experiments, single $200 \mathrm{~ms} / 50-200 \mathrm{~Hz}$ barrages were applied at specified times during the experiment to investigate changes in the spike responses of CA1 neurons (see Figs. 3 and 4). Applying such a single barrage induced neither synaptic LTP nor sAHP enhancement.

The voltage-clamp and current-clamp data were high-pass filtered at 0.3 and $3.0 \mathrm{kHz}$, respectively, and sampled at rates between 0.7 and $10.0 \mathrm{kHz}$, through a TL-1 DMA interface (Axon Instruments, Inc.). The pClamp programs (Axon Instruments, Inc.) were used to generate stimulus timing signals and transmembrane current pulses, and to record and analyze data. The mean peak values of control synaptic responses and control sAHP/sI ${ }_{\mathrm{AHP}}$ were calculated from all recordings prior to the application of a conditioning synaptic stimulation. These mean values were then used as a reference for the calculation of relative changes of synaptic response and

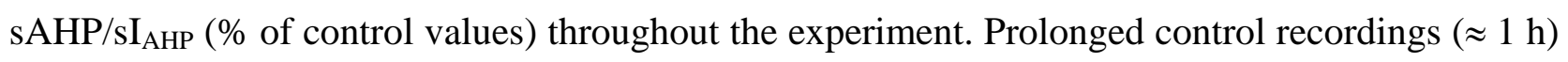
were also performed to check for the long-term stability of peak values of EPSP and sAHP/sI $\mathrm{AHP}_{\text {. }}$ The decay time constant $(\tau)$ of sAHP and of the underlying $\mathrm{sI}_{\mathrm{AHP}}$ recorded in the current-clamp 
and voltage-clamp modes, respectively, were calculated with single exponential fits of the decaying portion of the voltage and current trace. Statistical analysis was performed using the SigmaPlot program (SPSS Inc., Chicago, IL). Results are given as Mean \pm SEM in text and figures, and statistical significance was calculated by ANOVA tests. The significance $\mathrm{P}=0.05 ; 0.01$ and 0.001 values are indicated by $* * *$, and $* * *$, respectively in the figures.

Computer simulation. The simulation was performed using the NEURON program (Hines, 1994; Carnevale and Hines, 1997) that offers a powerful and flexible environment especially designed for the study of ionic currents and their effects on the integrative properties of neurons. Using this environment, we simulated two converging presynaptic SC inputs (SC1 and SC2) that connected the dendritic compartment of a CA1 pyramidal neuron model. The model was constructed according to the electrophysiological characteristics of the CA1 pyramidal neurons (e.g., Schwartzkroin, 1975; and see: Mainen et al., 1996). It consisted of four parts: (i) a simplified dendritic compartment, comprising 20 segments (length $=50 \mu \mathrm{m}$, diameter from $5 \mu \mathrm{m}$ near the soma to $1 \mu \mathrm{m}$ for the furthest segment), and synaptic contacts were simulated at compartment 2 and 10 from the soma; (ii) a spherical soma with a $60 \mu \mathrm{m}$ diameter; (iii) an axon composed of 50 segments (length=60 $\mu \mathrm{m}$, diameter from 5 to $1 \mu \mathrm{m}$, from the nearest to the furthest segment) where spikes were generated; and (iv) a passive intermediary segment (length=25 $\mu \mathrm{m}$, diameter $=1 \mu \mathrm{m}$ ) between the dendrite and the soma compartment. The passive segment was incorporated in order to counteract, to some extent, spike back-propagation. Each compartment comprised equally distributed leak channels that generated a leak current according to the equation

$$
I_{\text {leak }}=g_{\text {leak }} *\left(E_{m}-E_{\text {leak }}\right)
$$

where $I_{\text {leak }}$ is the current transported by the channels, $g_{\text {leak }}$ the conductance, $E_{m}$ the membrane potential, and $E_{\text {leak }}$ the reversal potential of the leak current. Active channels, based on Hodgkin and Huxley (1952)-type kinetics, were integrated in the axon and also sparsely in the soma.

The dendritic compartment contained the great majority $(99.99 \%)$ of the $\mathrm{sI}_{\mathrm{AHP}}$ channels distributed with a proximo-distal decreasing gradient (Sah and Bekkers, 1996; Bekkers, 2000). 
The remaining $\mathrm{sI}_{\mathrm{AHP}}$ channels $(0.01 \%)$ were located sparsely in the soma. Because our analysis concerned the sAHP, we also focused on the $\mathrm{Ca}^{2+}$ mechanisms that regulate the sAHP. Therefore, we added: L-type voltage-gated $\mathrm{Ca}^{2+}$ channels to the dendritic segment (for a review, see Magee et al., 1998) based on Goldman-Hodgkin-Katz-type kinetics (see Yamada et al., 1989); $\mathrm{Ca}^{2+}$ pumps that extrude $\mathrm{Ca}^{2+}$ ions out of the pyramidal neuron (Eakin et al., 1995); both radial and longitudinal diffusion mechanisms; and intracellular $\mathrm{Ca}^{2+}$ buffers (Regehr and Tank, 1992), the functioning of which was controlled by two constants according to the following equations

$$
\begin{aligned}
& \mathrm{Ca}^{2+}+\text { Buffer } \stackrel{k 1}{\longrightarrow} \mathrm{Ca} \bullet \text { buffer } \\
& \mathrm{Ca}^{2+}+\text { Buffer } \longleftarrow \text { } \longleftarrow \text { Ca } \bullet \text { buffer }
\end{aligned}
$$

where $k 1$ and $k 2$ are the rate constants regulating the velocity of capture and release, respectively, according to the intracellular $\mathrm{Ca}^{2+}$ concentration. Current pulses applied at two dendritic compartments simulated the effects of the activation of SC1 and SC2 on the CA1 neuron. The amplitude and duration of both pulses, which generated the depolarizations that simulated SCevoked excitatory postsynaptic potentials (EPSPs), were adjusted so that the response of the model neuron reproduced our physiological observations.

Both the LTP and the potentiation of the sAHP were induced when presynaptic and postsynaptic spikes coincided in time in the dendritic compartment. The LTP at either of the two converging synapses was simulated according to the following simple rules: (i) Using suprathreshold stimulation, as soon as 10 coincident pre- and postsynaptic spikes at a minimum instantaneous frequency of $40 \mathrm{~Hz}$ were detected, the pulse that generated the excitatory postsynaptic potential was incremented by $0.0008 \mathrm{nA}$ (which was slightly less than the initial threshold current value of $0.0009 \mathrm{nA}$ that elicited spikes without failures in the CA1 neuron in the absence of sAHP potentiation). (ii) Once the process was initiated (i.e., after rule $\boldsymbol{i}$ was fulfilled), each new coincident pre-postsynaptic spike pair occurring at the same minimum instantaneous frequency of $40 \mathrm{~Hz}$, increased the magnitude of the EPSP by incrementing the pulse by $0.0008 \mathrm{nA}$; 
this process being linear in the absence of spike failures. In other words, in control conditions a barrage of 40 suprathreshold stimuli delivered at $40 \mathrm{~Hz}$ by any SC input incremented the EPSP peak amplitude (i.e., by incrementing the pulse $\sim 0.025 \mathrm{nA}$ at the end of the 40 -spikes burst) in an LTP-like fashion, from the tenth to the fortieth pre-postsynaptic spike pairs. The potentiation of the sAHP followed similar rules and either involved (i) a $0.85 \%$ decrement of the buffering velocity of intracellular $\mathrm{Ca}^{2+}$ stores (buffer velocity, Fig. 6A), which allowed a longer lasting activation the $\mathrm{sI}_{\mathrm{AHP}}$ channels (cf., Borde et al., 1995), or (ii) a $0.25 \%$ increment of $\mathrm{sI}_{\mathrm{AHP}}$ channels closing time constant ( $\tau$; Fig. 6B), or (iii) both. The best simulation was obtained when both of the sAHP parameters were adjusted during and after the potentiation process and the time course of their changes was adjusted to display temporal profiles as those in real experiments (e.g., time course of $\mathrm{sI}_{\mathrm{AHP}}$ peak amplitude and $\tau$; Fig. 2B). In contrast, if there was no further synaptic stimulation the synaptic strengths remained constant after the end of the potentiation process.

Virtual intracellular current-clamp and $\mathrm{Ca}^{2+}$ concentration recordings were simulated in different parts of the model neuron in order to verify the behavior of the simulated cellular features (for instance, $\mathrm{Ca}^{2+}$ concentration variations and sAHP). However, only the voltage changes that occurred in the soma were considered in the present study.

\section{RESULTS}

Recordings were performed with patch electrodes from 120 CA1 pyramidal cells in voltageclamp conditions (mean Vr measured at zero holding current: $-55.4 \pm 0.6 \mathrm{mV}$ ) and with sharp electrodes from 69 CA1 pyramidal cells in the current-clamp configuration (mean Vr: -61.2 $\pm 3.0 \mathrm{mV}$ ). The other cellular characteristics (input resistance, firing threshold) were similar to those described previously (see Borde et al., 2000).

Heterosynaptic metaplasticity. In order to test the spatial and temporal characteristics of metaplasticity in rat hippocampus, intracellular current-clamp recordings with sharp electrodes 
were performed from single CA1 pyramidal neurons $(n=32)$ while two distinct SC afferent pathways (SC1 and SC2) were stimulated (Fig. 1A). Control subthreshold EPSPs were evoked by alternatively stimulating the SC1 and SC2 inputs with single pulses at a low rate of 0.2 per sec (see Methods). In control conditions SC1 EPSPs had amplitudes of $2.2 \pm 0.3 \mathrm{mV}(\mathrm{n}=10)$ and SC2 amplitudes were $1.8 \pm 0.5 \mathrm{mV}$, and there were no long-term modifications of peak EPSP amplitudes (112.6 $\pm 3.2 \%$ and $108.1 \pm 2.0 \%$ of control values, respectively $\sim 1 \mathrm{~h} ; \mathrm{n}=10$ ). Experiments were discarded when EPSPs fired spikes in control conditions. A tetanization conditioning protocol (see below) was then applied to the SC1 input to induce LTP, and single stimuli were applied (as the one used to record control EPSPs) at specified times during the experiment to test for changes in the synaptic efficacy of both SC1 and SC2. The same tetanization conditioning protocol was also applied to the SC2 pathway at various time points during the experiment while tests for changes in synaptic efficacy of SC1 and SC2 were repeated.

A group of similar experiments $(n=5)$ in which tetanization (see Methods) of the SC1 input was used to induce LTP (e.g., Bortolotto and Collingridge, 2000) are shown in Figure 1. Tetanization of the SC1 pathway (Fig. 1A and empty bar, Fig. 1B) induced the LTP of the SC1evoked EPSPs (a mean peak amplitude increment of $265.2 \pm 20.0 \%$, 30 min post-tetanization; p $<0.001 ; n=5$; empty circles, Fig. 1B), whereas the SC2-evoked EPSPs showed no statistically significant change from control values (mean peak amplitude $103.3 \pm 7.1 \%$, 30 min posttetanization; filled circles, Fig. 1B).

The homosynaptic LTP of the SC1 EPSPs lasted throughout the experiment (i.e., $>1 \mathrm{~h}$ ) in the absence of subsequent SC1 conditioning stimulation. The same tetanization protocol applied to the SC2 pathway 45-50 min after the SC1 tetanization (gray bar, Fig. 1B and E) did not induce changes in either EPSP, since the SC1-evoked EPSPs remained potentiated $285.5 \pm 13.7 \%$, 50 min post-SC1 tetanization; $\mathrm{p}<0.001$; same cells) and the amplitude of the SC2-evoked EPSPs was not significantly modified (96.7 $\pm 7.2 \%)$. However, re-applying the tetanization protocol to SC2 afferents 15-20 min later (i.e., > 1 h after the SC1 tetanization; black bar, Fig. 1B) induced a 
significant LTP of the SC2-evoked EPSP (128.8 $\pm 4.2 \%$; $<0.001$; same cells) that lasted throughout the rest of the experiment (see also Fig. 1E). Interestingly, depending on the time elapsed from the tetanization of the SC1, tetanization of the SC2 input either failed to or induced the LTP of the SC2 input.

The above results suggest that a metaplastic phenomenon occurred by which the induction of LTP at the SC1 input exerted a negative regulation of the ability of SC2 tetanization to induce LTP. The negative control for the induction of SC2 LTP was removed with the time elapsed after the SC1 conditioning stimulation, thus eventually allowing the SC2 input to display LTP after several tens of minutes.

Simultaneous induction of LTP and sAHP potentiation. During the experiments described above we also analyzed whether the sAHP contributed to the heterosynaptic metaplasticity ( $\mathrm{n}=32)$. Depolarizing current pulses were applied through the recording microelectrode to evoke an sAHP at specified timed during the experiment (see Methods), and the sAHP peak amplitude was measured 150 ms after the offset of the pulse, i.e. when the medium AHP had almost completely deactivated (for a review, see Storm, 1990). The magnitude of the sAHP did not change significantly during prolonged recordings in control conditions (triangles, Fig. 1C). Control sAHP peak amplitude values were $5.3 \pm 2.1 \mathrm{mV}$ and $4.9 \pm 3.1 \mathrm{mV}$ (averages of 5 responses $20 \mathrm{~min}$ and 1 $\mathrm{h}$ after impaling the cell; $\mathrm{n}=6$ ). We also monitored the changes in the peak amplitudes of the sAHP at specified times during the experiment before and after the conditioning tetanization protocol was applied (filled circles, Fig. 1C). The SC1 tetanization protocol (empty bar, Fig. 1C) that generated the SC1 LTP also triggered a potentiation of the sAHP (filled circles: $165.8 \pm 3.2 \%$; $\mathrm{p}<0.001 ; \mathrm{n}=5$ ) that lasted $>50$ min before it returned close to control values. The number of spikes evoked by the depolarizing current pulses that evoked the sAHP did not change throughout the experiment (7.40 \pm 0.54 and $7.32 \pm 0.55$; averages of 8 responses before and after tetanization, respectively; $n=8$ ), implying that the sAHP potentiation was not caused by an increased spike response. Interestingly, the LTP of the SC2 input could occur only after the sAHP potentiation 
faded (Fig. 1B and E). Examples of control and potentiated averaged SC1-evoked EPSPs and sAHP are illustrated in Figure 1D.

Results as those shown in Fig. 1 were recorded in 17 out of 32 experiments (or $53 \%$ ). In the other 15 cells (or $47 \%$ ) although the homosynaptic LTP was present, no clear sAHP amplitude variations were detected. Indeed, the SC1-evoked EPSP showed LTP when all the cells were considered (169.4 $\pm 33.3 \%$; $<<0.001 ; n=32$ ), whereas the sAHP increased significantly only in a group of those neurons $(141.9 \pm 10.5 \%$; $<<0.001$; $n=17)$. Nevertheless, tetanization of the SC2 afferents never induced LTP $(98.4 \pm 2.5 \%$; $n=17)$ when the sAHP was potentiated by prior SC1 conditioning (Fig. 1E, left), whereas the same protocol applied after the sAHP returned close to control value (105.9 $\pm 6.7 \%)$ always triggered LTP of the SC2 input $(130.6 \pm 9.3 \%$; $<0.001$; same cells; Fig. 1E, right). Therefore, when SC1 tetanization induced the potentiation of the sAHP the described heterosynaptic metaplasticity consisting in the block of the induction of LTP at the SC2 input was always observed. However, in cells where the sAHP was not potentiated by tetanization of the SC1 input, tetanization of the SC2 readily induced LTP of these afferents (139.7 $\pm 16.5 \%$; $n=6$ ) even at short delays after the SC1 tetanization. Therefore, the above results suggest a causal relationship between the potentiation of the sAHP and the heterosynaptic metaplasticity.

The magnitude of the LTP of the SC1 and SC2 EPSPs was different (compare SC1: 226.1 $\pm 17.1 \%$; $<0.001 ; n=5$; and SC2: $126.9 \pm 5.2 \%$; $<0.001 ; n=5)$. In addition, since the LTP of the SC2 EPSPs could only be potentiated when the sAHP had declined to control values, the delay required to induce LTP at the SC2 input also varied somewhat (52 $\pm 8 \mathrm{~min}$; same cells). Although we did not analyze the causes of these differences they may reside in uncontrolled factors, such as cellular variations or the different initial magnitudes of the sAHP and synaptic strengths.

In order to reduce the possible contamination by voltage-sensitive conductances, whole-cell voltage-clamp experiments were performed. Neither the magnitude of the $\mathrm{sI}_{\mathrm{AHP}}(140.5 \pm 20.3 \mathrm{pA}$ and $136.9 \pm 18.4 \mathrm{nA} ; 5 \mathrm{~min}$ and $1 \mathrm{~h}$ after access to the intracellular compartment; $\mathrm{n}=6$ ) nor the amplitude of the EPSCs (50.7 \pm 10.9 pA and $45.2 \pm 14.7$ pA; same time points, same cells) changed 
significantly during prolonged recordings of $>1 \mathrm{~h}$ in control conditions. Both the SC-evoked EPSCs and the $\mathrm{sI}_{\mathrm{AHP}}$ were also monitored regularly before and after a conditioning tetanization protocol was applied to an SC pathway after transiently switching to the current-clamp mode ( $n=31$; see Methods). The time course of both the LTP of the SC1 EPSC (empty circles: 203.8 $\pm 5.1 \%$ at 20 min post-tetanization; $\mathrm{p}<0.001 ; \mathrm{n}=6$ ) and the potentiation of the $\mathrm{sI}_{\mathrm{AHP}}$ (filled circles: $150.9 \pm 5.2 \%$ at 20 min post-tetanization; $\mathbf{p}<0.001$; same cells) are shown in Figure $2 \mathbf{A}$. In the voltage-clamp configuration, more than $71 \%$ of the cells (22 out of 31 neurons) showed significant LTP and $\mathrm{sI}_{\mathrm{AHP}}$ potentiation, and grouped results showed mean increases in peak EPSC amplitude of $252.1 \pm 43.3 \%(\mathrm{p}<0.01)$ and $\mathrm{sI}_{\mathrm{AHP}}$ amplitude of $167.9 \pm 12.1 \%(\mathrm{p}<0.001)$. The $\mathrm{sI}_{\mathrm{AHP}}$ potentiation developed without significant changes in the responses evoked by the depolarizing command pulses because the number of unclamped action currents varied only slightly throughout the experiment (102.2 $\pm 3.3 \%$ of the initial control value $\approx 1 \mathrm{~h}$ after impaling the cell; $\mathrm{n}=6$ ), implying that the potentiation was not caused by an increased response evoked by the depolarizing current pulse.

The similarities of the voltage-clamp and current-clamp results suggest that the observed synaptic and sAHP plasticities (e.g., Figs. 1 B and $\mathbf{C}$ ) were not caused by modification of the driving force, and support a causal relationship between the described metaplasticity and the potentiation of the $\mathrm{sAHP} / \mathrm{sI}_{\mathrm{AHP}}$.

Synaptic tetanization increases both the amplitude and duration of the SAHP. As shown above in Figures 1D and 2A, both the amplitude and duration of the sAHP were modified by the SC1 tetanization. In order to confirm this observation, we monitored the peak amplitude and the decay time constant of the $\mathrm{sI}_{\mathrm{AHP}}$ in voltage-clamp conditions, before and after tetanization of the SC input (Fig. 2B). The $\mathrm{sI}_{\mathrm{AHP}}$ peak amplitude increased by $175.9 \pm 15.2 \%(\mathrm{p}<0.001 ; \mathrm{n}=11)$ within the first 20 min post-SC tetanization and then decreased to return to control values $\approx 50$ min after the tetanization. The $\mathrm{sI}_{\mathrm{AHP}}$ decay time constant also increased to peak $40 \mathrm{~min}$ after the tetanization reaching $305.8 \pm 53.3 \%$ of control value $(\mathrm{p}<0.001$; same cells) and remained potentiated $\approx 60$ min 
after. These differences in profile suggest that at least two cellular mechanisms account for the observed $\mathrm{sI}_{\mathrm{AHP}}$ potentiation, one affecting the magnitude of the sAHP current (i.e., the number of open $\mathrm{sI}_{\mathrm{AHP}}$ channels), the other the duration of the current (i.e., the kinetics of $\mathrm{sI}_{\mathrm{AHP}}$ channels).

Interestingly, a parallel LTP and sAHP potentiation could also be observed using other LTP conditioning protocols. Pairing a low frequency stimulation with postsynaptic depolarization to $0 \mathrm{mV}$ (LFSD; e.g., Otmakhov et al., 1997) induced both the LTP of the SC-evoked EPSCs (124.9 $\pm 5.2 \% ; \mathrm{n}=3 ; \mathrm{p}<0.001)$ and the simultaneous potentiation of the $\mathrm{sI}_{\mathrm{AHP}}(184.6 \pm 29.2 \%$; $\mathrm{n}=3$; p<0.05) measured 15 min post-LFSD under voltage-clamp (e.g., Fig. 2C). Theta-burst stimulation (TBS; e.g., Hoffman et al., 2002) also induced both the LTP of SC-evoked EPSCs (227.1 $\pm 27.2 \%$; $\mathrm{n}=3 ; \mathrm{p}<0.001)$ and the parallel $\mathrm{sI}_{\mathrm{AHP}}$ potentiation $(199.9 \pm 15.3 \% 15 \mathrm{~min}$ after a TBS; $\mathrm{n}=3$; p $<0.001$; e.g., Fig. 2D). Therefore, whatever the LTP induction protocol used in our study, a parallel potentiation of the synaptic response and of the sAHP/sI $\mathrm{I}_{\mathrm{AHP}}$ was induced.

Changes in excitability and spike firing parallel the potentiation of the SAHP. According to Hebb’s postulate (Hebb, 1949), a temporal association between pre- and post-synaptic spike firing is required to induce LTP. Because the sAHP regulates action potential firing we investigated under current-clamp conditions the possible correlation between the synaptically induced sAHP enhancement and changes in the pyramidal neuron firings. A group of pyramidal neurons $(n=20)$ were slightly depolarized by intracellular current injection to evoke a steady low rate spike activity (9.4 $\left.\pm 0.4 \mathrm{sec}^{-1}\right)$ and a depolarizing pulse (0.1-0.5 nA; $\left.200 \mathrm{~ms}\right)$, which generated a burst of spikes followed by a large compound sAHP (Fig. 3A), was added at specified times during the experiment. In those conditions, after tetanization of a SC pathway the CA1 neuron spike activity was dramatically affected. Between 10 and $30 \mathrm{~min}$ post-tetanization, which coincides on the average with the maximum potentiation of the sAHP (see above), there was a marked rise in the inter-spike intervals (ISI) during the sAHP and specially of the delay (d) to the post-burst spike (Fig. 3A, and Fig. 3B).

In 12 experiments, the firing capacity of CA1 neurons during an evoked sAHP was also 
tested 15 minutes after an SC tetanization and showed a mean firing rate $37.1 \pm 10.2 \%$ of control $(\mathrm{p}<0.001)$ when the sAHP peak amplitude increased up to $161.8 \pm 21.3 \%(\mathrm{p}<0.05$; same cells $)$ (group 1, Fig. 3C,). In contrast, in the absence of sAHP potentiation (100 $\pm 8.1 \%$ ) the mean firing was not significantly altered (112 \pm 4.1 ; group 2 , Fig. $3 C$ ). Similarly, the delay (d) to the first spike following the current pulse-generated burst also increased from $0.20 \pm 0.01$ to $0.45 \pm 0.05 \mathrm{~s}$ $(\mathrm{p}<0.05 ; \mathrm{n}=8) 13$ min post-tetanization. On the average $\boldsymbol{d}$ was highest between 10 and 20 min posttetanization (n=3; Fig. 3D); i.e. when the sAHP and $\mathrm{sI}_{\mathrm{AHP}}$ were maximally potentiated following the conditioning stimulation (see above). Interestingly, in each case the stronger reduction in spike firing coincided in time with the highest potentiation of the sAHP (i.e., 10 - 20 minutes posttetanization).

These results suggest that the sAHP potentiation can modulate for several tens of minutes the spike response evoked by SC stimulation by decreasing the postsynaptic excitability and increasing spike frequency adaptation. In this scenario, especially relevant are the increased postsynaptic spike failures of the non-potentiated SC2 input during stimulation with barrages. When single $200 \mathrm{~ms}$ barrages (as the ones that were repeatedly presented to evoke LTP) were applied to the SC2 input during the potentiated sAHP (lower records, Fig. 4A) some of the EPSPs evoked by the presynaptic barrage were suprathreshold and triggered spikes (especially at stimulation on). Each postsynaptic spike was followed by a larger than control sAHP (i.e., potentiated) that hyperpolarized the neuron so that subsequent SC2-evoked EPSPs were subthreshold and failed to trigger spikes (upper records, Fig. 4A). In many cases the barrage evoked only one spike when the sAHP was fully potentiated (e.g., Fig. 4D).

As the potentiation of the sAHP faded with time more spikes were triggered by the SC2 barrage, because spikes were followed by smaller sAHP that, on the average, hyperpolarized the cell less after each spike (Fig. 4A and D). Although this analysis was with isolated SC2 barrages, similar mechanisms were at work when repeated SC2 barrages failed to induce LTP (not shown). Therefore, the potentiated sAHP caused a reduction of excitability and, thus, of the probability of 
temporal association between pre- and postsynaptic firing that is required to induce LTP. Consequently, a potentiated sAHP may prevent the induction of LTP by stimulation with repeated barrages of the SC2 input. Conversely, similar repeated barrages could evoke sufficient postsynaptic spikes to induce the LTP of the SC2 EPSP when the sAHP potentiation had faded (Fig. 4D) or when it had not been potentiated by the SC1 tetanization (see above).

We tested this assumption by tetanization of the SC1 input to induce the homosynaptic LTP and potentiate the SAHP. When the sAHP showed clear potentiation, the SC2 pathway was stimulated with single barrages repeated every $5 \mathrm{~min}$. In these conditions the cell slowly recovered its capacity to fire spikes in response to SC2 barrages as the amplitude of the potentiated sAHP gradually decayed with time (Fig. 4C). As a result of this gradual recovery of excitability, the average postsynaptic spike frequency evoked by the SC2 barrages showed a negative relationship with the amplitude of the potentiated sAHP evoked by the burst itself, which corroborated our hypothesis (Fig. 4C).

Following the induction of LTP of the SC1 input (228.5 $\pm 26.0 \%$; $=5)$ and potentiation of the sAHP (172.7 $\pm 29.3 \%$; same cells) we also analyzed the responses evoked by a single barrage applied at the non-potentiated SC2 input. This single barrage was identical to those that were repeatedly presented to evoke LTP (see Methods). In those conditions a single barrage applied at the SC2 afferents evoked considerably fewer spikes than the SC1 conditioning stimulation (24.2 $\pm 5.2 \%$; p 0.001; n=5) (Fig. 4C, D and $\mathbf{E}$ ). The same barrage applied repetitively did not induce the LTP of the SC2 afferents (105.3 $\pm 13.3 \%$; not shown, but see above). In contrast, 50 min later when the sAHP potentiation had faded, the same conditioning stimulation applied to the SC2 input evoked many more spikes (262.1 $\pm 83.3 \%$; p<0.05; n=5) (Fig. 4C, D and E), and when repeated induce the LTP of the SC2-EPSPs (200.8 $\pm 26.0 \%$; n=5; not shown, but see above). In every case, the LTP of the SC2 input was observed only when the sAHP had recovered its control amplitude, and the SC2 conditioning stimulation evoked as many postsynaptic spikes as the SC1 conditioning 
stimulation (ANOVA test showed no significant differences) (e.g., first and last traces in Fig. 4C and $\mathbf{D})$.

We tested whether increasing the SC2 barrage frequency could increase the spike response during a potentiated sAHP and thus overcome the block of the LTP induction caused by a potentiated sAHP. In control conditions increasing the frequency of the SC2 stimulation increased both the depolarization and the number of spikes evoked by the SC burst, by incrementing the EPSPs temporal summation without changing the presynaptic fibers being stimulated. We stimulated the SC2 input with $200 \mathrm{~ms}$ barrages at identical intensity and 50, 100 and $200 \mathrm{~Hz}$. There were no significant difference in the number of spikes elicited by the barrages (4.16 $\pm 0.83 \mathrm{~Hz}, 4.66 \pm 0.33 \mathrm{~Hz}, 6.60 \pm 1.66 \mathrm{~Hz}$, respectively) when the sAHP was potentiated (Figs. 4C, $\mathbf{D}$ and $\mathbf{E})$, and there was no LTP induction at the SC2 input (n=5).

We also tested the effects of increasing the intensity of the SC2 barrage that raises the number of presynaptic fibers stimulated and therefore increases spatial summation. The summated SC2 EPSPs could intensify the postsynaptic spike response and overcome the block of the LTP by the potentiated sAHP. We tested this second possibility by incrementing the SC2 barrage intensity up to $1.5 \mathrm{x}$ and $2.0 \mathrm{x}$ of control intensities. The increased stimulation intensities only induced small changes in the number of spikes while the sAHP was potentiated (from $5.1 \pm 1.6 \mathrm{~Hz}$ in control to $6.8 \pm 1.2 \mathrm{~Hz}$ at $1.5 \mathrm{x}$, and to $6.3 \pm 1.1 \mathrm{~Hz}$ at $2.0 \mathrm{x}$; Fig. 4F), and LTP induction was still prevented at the SC2 synapses $(n=5)$.

Therefore, the above results suggest that the decreased excitability caused by the potentiated sAHP exerted a strong control on spike firing that prevented the LTP of the SC2 input and that could not be overcome by incrementing the frequency or the intensity of the presynaptic SC2 barrage.

Effects of blocking NMDA and L-type voltage activated $\mathrm{Ca}^{2+}$ channels. The LTP in glutamatergic synapses on CA1 pyramidal neurons may depend on both $\mathrm{Ca}^{2+}$ inflow through NMDA channels and via voltage-activated $\mathrm{Ca}^{2+}$ channels (e.g., Grover and Teyler, 1990; Bliss and 
Collingridge, 1993; Hanse and Gustafsson, 1995; Cavus and Teyler, 1996; Magee and Johnston, 1997). Influx of $\mathrm{Ca}^{2+}$ through L-type voltage-activated $\mathrm{Ca}^{2+}$ channels and to a lesser extent via NMDA channels (Tanabe et al., 1998; Borde et al., 2000; Lancaster et al., 2001; Shah and Haylett, 2002) may also contribute to the activation of the $\mathrm{sAHP} / \mathrm{sI}_{\mathrm{AHP}}$. Therefore, up-regulation of $\mathrm{Ca}^{2+}$ influx both through NMDA or L-type $\mathrm{Ca}^{2+}$ channels by the tetanization of SCs could mediate the potentiation of the sAHP/sI $\mathrm{AHP}_{\mathrm{H}}$ and contribute to the LTP. We tested the effects of inhibition of NMDA channels with AP-5 $(50 \mu \mathrm{M})$ and of L-type voltage-activated $\mathrm{Ca}^{2+}$ channels with nimodipine (20 $\mu \mathrm{M})$. Whereas block of L-type channels prevented the potentiation of the sAHP (110.7 $\pm 12.0 \%$; $n=6$ ) without preventing the LTP of the SC1 input (338.3 $\pm 23.0 \%$; same cells; Fig. 5A, B), AP-5 had no effect on the sAHP (131.9 $\pm 5.9 \%$; $n=6)$ and did not block the LTP (172.6 \pm 11.9 \%; n=6; Fig. 5C and D). However, simultaneous superfusion of nimodipine and AP5 inhibited both the sAHP/sI $\mathrm{AHP}_{\mathrm{AH}}$ potentiation and the synaptic LTP $(99.0 \pm 4.6 \%$ and $101.0 \pm 12.5$ $\%$, respectively; $\mathrm{n}=6$, not shown). These results suggest a contribution of $\mathrm{Ca}^{2+}$ influx through Ltype channels in the potentiation of the sAHP/sI $\mathrm{AHP}_{\text {, whereas }} \mathrm{Ca}^{2+}$ influx via NMDA channels does not participate in the potentiation of the $\mathrm{sAHP} / \mathrm{sI}_{\mathrm{AHP}}$ (see Discussion).

Contribution of the SAHP potentiation in heterosynaptic metaplasticity (simulation). Using a realistic SCs-CA1 model (see Methods), we investigated the role of the sAHP potentiation in the control of LTP induction in current-clamp conditions.

Our physiological observations were best simulated when both the $\mathrm{Ca}^{2+}$ buffering velocity in the postsynaptic CA1 pyramidal neuron (Fig. 6A) and $\mathrm{sI}_{\mathrm{AHP}}$ channels closing time constant $\tau$ (Fig. 6B) were modified by the synaptic conditioning (see Methods). Initially, the weights of both simulated SC1 and SC2 were set to identical threshold values and responded without spike failures to presynaptic stimulation (1-to-1 pre-postsynaptic coincidence) at resting potential. The same SC1 and SC2 stimulations failed to evoke spikes during a sAHP that followed a spike burst evoked by a depolarizing current pulse injected into the soma (2.0 nA/200 ms; not shown). Then, a 
conditioning stimulation (40 impulses at $40 \mathrm{~Hz}$ ) was applied to SC1 and evoked a synchronized $40 \mathrm{~Hz}$ input-output spike sequence that fulfilled the criteria for inducing both the LTP of SC1 and the potentiation of sAHP (Fig. 6C and D, SC1 1 Tetanus; see Methods). When both the SC1 LTP and the sAHP potentiation had developed, the same stimulation (40 impulses at $40 \mathrm{~Hz}$ ) was applied first to SC2 and 3 s after to SC1, to test for changes in synaptic efficacy (Fig. 6C and D, SC2 Tetanus and $\mathrm{SC}_{2}$ Tetanus, respectively). Stimulation of the non-potentiated SC2 input induced a brief spike burst (Fig. 6C and D, SC2) at an instantaneous spike frequency well under the $40 \mathrm{~Hz}$ required to trigger LTP and sAHP potentiation. Whatever the stimulation frequency of the non-potentiated SC2 input that we tested (up to $200 \mathrm{~Hz}$; not shown), the cell only fired a brief initial burst at an instantaneous frequency lower than the threshold frequency required for inducing LTP (not shown). This simulated result closely parallels the biological consequences of increasing the SC2 barrage frequency in the biological situation (see above Fig. 4D and E).

The failure of the SC2 tetanization to induce the LTP was caused by the rapid summation of the larger, potentiated, unitary sAHPs that were triggered by the first postsynaptic spikes in the burst. The summated sAHP hyperpolarized the cell so that subsequent SC2-evoked EPSPs were unable to trigger spikes. In contrast, the previously tetanized SC1 input, which had developed LTP, generated EPSPs larger enough to overcome the potentiated sAHP, and the presynaptic spike train was still able to evoke a sustained burst of postsynaptic spikes (Fig. 6C, D, $\mathrm{SC}_{2}$ ). Therefore, whereas the $40 \mathrm{~Hz}$ stimulation of SC2 did not reach the criteria for LTP induction when the sAHP was potentiated, the same stimulation applied to the potentiated SC1 input was still able to induce the LTP even in the condition of potentiated sAHP.

The above simulation closely models the biological results illustrating how tetanization of a non-potentiated synaptic input may be unable to induce LTP if the neuronal excitability is depressed by a potentiated sAHP, whereas a similar stimulation of the potentiated synaptic input could still evoke sufficient postsynaptic firing (due to the LTP). This latter observation is consistent with a gating phenomenon in which the potentiated synapses can elicit postsynaptic 
spiking, whereas non-potentiated synapses remain 'blocked' postsynaptically by the larger sAHP.

This suggests further a role of the synaptically evoked sAHP enhancement in the selection of convergent inputs by which the physiologically reliable potentiated input may be amplified while the influence of any other input would be repressed.

\section{DISCUSSION}

We show that the induction of LTP by classical conditioning protocols triggers a prolonged $(\approx 1 \mathrm{~h})$ potentiation of the sAHP mediated by the enhancement of the underlying slow $\mathrm{Ca}^{2+}$ activated $\mathrm{K}^{+}$current, $\mathrm{sI}_{\mathrm{AHP}}$. This $\mathrm{sAHP} / \mathrm{sI}_{\mathrm{AHP}}$ potentiation reduces excitability and increases spike frequency adaptation, thus decreasing the capacity of the cell to fire prolonged spike bursts. The reduced spike firing prevents subsequent tetanization protocols to generate an LTP at other nonpotentiated synaptic input, without modifying the previously potentiated synapses. Therefore, this potentiation of the sAHP, which is triggered by brief periods of synaptic activity and relies on modifications of an intrinsic property, represents a novel cellular mechanism engaged in heterosynaptic metaplasticity of synaptic efficacy at CA3-CA1 pyramidal neuron synapses.

Plasticity of the sAHP. An activity-dependent modulation of the $\mathrm{sAHP} / \mathrm{sI}_{\mathrm{AHP}}$ has been described in CA1 pyramidal neurons as a brief facilitation (3-8 min) induced either by intracellular current injection or excitatory synaptic stimulation (Borde et al., 1995, 1999, 2000). We demonstrate here that a synaptic stimulation that induces LTP may generate a longer lasting potentiation of the sAHP. Interestingly, the recent demonstration that both facilitation and depression of the sAHP may be induced by tetanic and theta burst stimulation with injected current in CA1 pyramidal neurons (Kaczorowski et al., 2003), suggests a possible bidirectional control of postsynaptic excitability by the $\mathrm{sAHP} / \mathrm{sI}_{\mathrm{AHP}}$.

Several studies have related the amplitude of the sAHP to learning and memory (e.g., Coulter et al., 1989; Disterhoft et al., 1996; for a recent review see Wu et al., 2002). They showed that a reduction of the sAHP in CA1 pyramidal neurons occurs several hours to days after classical 
conditioning. This decline of the sAHP may facilitate subsequent learning (Coulter et al., 1989;

Saar et al., 1998; Oh et al., 2003; for recent reviews see Wu et al., 2002; Daoudal and Debanne, 2003; Zhang and Linden, 2003). In addition, an age-related enhancement of the sAHP in CA1 hippocampal pyramidal neurons has also been associated with learning deficits (e.g., Disterhoft et al., 1996; Meredith et al., 2002; see also Pike et al., 1999).

The synaptically-evoked sAHP potentiation (present Results) and the above discussed learning-related sAHP depression represent different phenomena that exert opposed effects on cellular excitability and that occur early ( $<1 \mathrm{~h}$; present Results) and late, respectively.

Rapid increases in neuronal excitability associated with the induction of LTP have also been described (e.g., Bliss and Lomo, 1973; Armano et al., 2000; Egorov et al., 2002; for recent reviews see Daoudal and Debanne, 2003; Zhang and Linden, 2003). These increases in excitability are input specific -i.e., are exclusively associated with stimulation of the potentiated synaptic input-, whereas a decreased excitability is coupled with stimulation of convergent but non-potentiated synaptic inputs (e.g., Cavus and Teyler, 1996; Daoudal et al., 2002; Wang et al., 2003). The input specificity suggests that the intrinsic excitability of different dendritic areas may be up- or downregulated in an activity-dependent manner. Although different mechanisms have been proposed for the above discussed effects, the phenomenological similarities with the heterosynaptic metaplasticity described here suggests that the latter may represent an example of input specificity caused by the potentiation of the $\mathrm{sAHP} / \mathrm{SI}_{\mathrm{AHP}}$ or of the voltage-gated $\mathrm{Ca}^{2+}$ channels that activate the $\mathrm{sAHP} / \mathrm{SI}_{\mathrm{AHP}}$ at specific dendritic regions (e.g., Yasuda et al., 2003; for a review see Daoudal and Debanne, 2003).

Cellular mechanisms mediating the potentiation of the SAHP. The ionic channels mediating the $\mathrm{sI}_{\mathrm{AHP}}$ are thought to be located mainly on dendrites close to the soma of hippocampal pyramidal neurons (Sah and Bekkers, 1996; Bekkers, 2000), suggesting a role for the sAHP/sI $\mathrm{AHP}_{\mathrm{A}}$ in controlling dendritic excitability and spike back-propagation (Hoffman et al., 1997; Magee and Carruth, 1999). Interestingly, the blockade of the sAHP by the $\beta$-adrenergic agonist 
isoprenaline, the metabotropic glutamate receptor agonist $t$-ACPD or the cholinergic agonist carbachol facilitates the induction of LTP (e.g., Hasselmo and Barkai, 1995; Sah and Bekkers, 1996; Cohen et al., 1999). Unfortunately, we could not use such nonspecific sAHP blockers because these drugs also modulate the release of glutamate from CA3 terminals (e.g., Fernández de Sevilla et al., 2002, 2003), and we would not have been able to conclude if the effects were due to the postsynaptic block of the sAHP or to a presynaptic regulation of glutamate release from SC terminals. Nevertheless, our simulation experiments are consistent with the proposed role for the sAHP potentiation in the down-regulation of LTP induction at non-potentiated synapses through the reduction of excitability (see also Pike et al., 1999).

The channels mediating $\mathrm{sI}_{\mathrm{AHP}}$ are voltage insensitive, and the kinetics of the $\mathrm{sI}_{\mathrm{AHP}}$ closely parallel the changes in intracellular concentration of $\mathrm{Ca}^{2+}\left(\left[\mathrm{Ca}^{2+}\right]_{\mathrm{i}}\right)$ caused by action potential activity (Regehr and Tank, 1992; Sah and Isaacson, 1995; Martin et al., 2001; Carrer et al., 2003). During the $\mathrm{sI}_{\mathrm{AHP}}$ potentiation there are changes in the amplitude and deactivation kinetics that follow different time courses (present Results), suggesting that at least two cellular mechanisms are contributing. The amplitude changes probably reflect the number of open $\mathrm{sI}_{\mathrm{AHP}}$ channels related to $\left[\mathrm{Ca}^{2+}\right]_{\mathrm{i}}$, and the kinetic modifications are most likely caused by changes of the $\mathrm{Ca}^{2+}$ sensitivity of the channels.

The activation of the $\mathrm{sAHP} / \mathrm{sI}_{\mathrm{AHP}}$ is mainly dependent on $\mathrm{Ca}^{2+}$ influx through $\mathrm{L}$-type $\mathrm{Ca}^{2+}$ channels in hippocampal pyramidal neurons, and inhibition of L-type channels with dihydropyridines markedly reduces the sAHP/sI $\mathrm{AHP}_{\mathrm{AHP}}$ (Tanabe et al., 1998; Borde et al., 2000) and blocks the brief sAHP/sI $\mathrm{AHP}_{\mathrm{AP}}$ potentiation induced by repeated activation of CA1 pyramidal neurons (Borde et al., 2000). Inhibition of L-type channels with nimodipine also blocks the sAHP/sI $\mathrm{AHP}_{\mathrm{H}}$ potentiation induced by SC tetanization without affecting the LTP induction (present Results), suggesting that similar cellular mechanisms may be at work in both cases and that the modulation of $\mathrm{Ca}^{2+}$ influx through L-type channels may play a key role in regulating the magnitude of the 
sAHP/sI $I_{\text {AHP }}$ (see also Carrer et al., 2003). Therefore, $\mathrm{Ca}^{2+}$ influx through L-type channels appears to be crucial in the genesis of this form of heterosynaptic metaplasticity.

An additional possibility is that firing activity can also induce $\mathrm{Ca}^{2+}$ release from intracellular stores in hippocampal pyramidal cells by the mechanism of $\mathrm{Ca}^{2+}$-induced $\mathrm{Ca}^{2+}$ release (e.g., Jacobs and Meyer, 1997), and the $\mathrm{Ca}^{2+}$ released may contribute both to the activation and subsequent potentiation of the $\mathrm{sAHP} / \mathrm{sI}_{\mathrm{AHP}}$ (Borde et al., 2000). Consequently, $\mathrm{Ca}^{2+}$ influx through L-type $\mathrm{Ca}^{2+}$ channels may directly activate the sAHP/sI ${ }_{\mathrm{AHP}}$ (e.g., Tanabe et al., 1998; Borde et al., 2000; Carrer et al., 2003; present Results) and also indirectly increase intracellular $\mathrm{Ca}^{2+}$ via release from intracellular stores.

Influx of $\mathrm{Ca}^{2+}$ through NMDA channels may contribute to the LTP (e.g., Bliss and Collingridge, 1993; Magee and Johnston, 1997) and may also be sufficient to activate the $\mathrm{sI}_{\mathrm{AHP}}$ (Lancaster et al., 2001; Shah and Haylett, 2002). Since the NMDA conductance may be enhanced during plasticity (Vogt et al., 1997), one may suggest a link with the $\mathrm{sI}_{\mathrm{AHP}}$ potentiation. However, we found no evidence of this possibility because blocking the NMDA channels with AP-5 did not prevent the potentiation of the $\mathrm{SAHP} / \mathrm{SI}_{\mathrm{AHP}}$ and did not block the LTP induced by tetanization protocols. Simultaneous block of both NMDA and L-type channels was required to inhibit the LTP (Present Results; see Grover and Teyler, 1990; Hanse and Gustafsson, 1995; Cavus and Teyler, 1996).

Synaptic plasticity and sAHP potentiation. Recent reports have shown that the $\mathrm{SAHP} / \mathrm{SI}_{\mathrm{AHP}}$ may reduce the capacity of the CA1 neuron to respond to prolonged high frequency synaptic input (Lancaster et al., 2001), a result that is consistent with the demonstration that a potentiated sAHP reduces postsynaptic firing and prevents the induction of LTP at non-potentiated synaptic inputs (present Results; see also Borde et al., 1999; Carrer et al., 2003).

Evidence has accumulated indicating the pivotal role of the combined effects of backpropagating spikes and $\mathrm{Ca}^{2+}$ inflow in the induction of "hebbian” synaptic plasticity (e.g., Magee and Johnston, 1997; Markram et al., 1997; Linden, 1999; Pike et al., 1999). Our results suggest 
that potentiation of the $\mathrm{sAHP} / \mathrm{sI}_{\mathrm{AHP}}$ could prevent the induction of LTP by regulating these processes. Firstly, of key importance is the inverse relationship between the potentiation of the sAHP and the effectiveness of EPSP barrages to evoke spikes (present Results; Pike et al., 1999). Secondly, the $\mathrm{sI}_{\mathrm{AHP}}$ is ideally located in the dendrites close to the soma of CA1 pyramidal neurons to oppose back-propagating spikes (Sah and Bekkers, 1996; Bekkers, 2000), which may reduce the probability of temporal association between pre- and postsynaptic activity. Consistent with this latter hypothesis, both spike back-propagation and LTP induction are enhanced by the activation of muscarinic cholinergic receptors that block the $\mathrm{sI}_{\mathrm{AHP}}$ (e.g., Tsubokawa and Ross, 1999; see also Linden, 1999).

The $\mathrm{sI}_{\mathrm{AHP}}$ channels are targets for several protein kinases and phosphatases (for a review, see Levitan, 1994) and several transmitters regulate the $\mathrm{sI}_{\mathrm{AHP}}$ via the activation of these enzymes (e.g., Pedarzani et al., 1998, 2001). The same kinases and phosphatases are also crucial for the induction of LTP (for a review see Tokuda and Hatase, 1998), suggesting that shared second messenger pathways may contribute to both the LTP and the $\mathrm{sI}_{\mathrm{AHP}}$ potentiation. The apparent input specificity of the heterosynaptic metaplasticity described here may depend on the up- or down-regulation of the $\mathrm{sI}_{\mathrm{AHP}}$ via activation of kinases and phosphatases at specified dendritic sites. This possibility, of great functional importance, remains to be investigated.

In conclusion, we propose that the activity-dependent regulation of the sAHP/sI $\mathrm{AHP}_{\text {may }}$ play a key role during the early phase of information storage by selecting the functionally reliable synaptic input to remain potentiated, whereas potentiation of other inputs would be temporarily prevented, thus favoring information flow through specific pathways within the network. 


\section{ACKNOWLEDGMENTS}

Drs. D. Le Ray and D. Fernández de Sevilla contributed equally to the experimental work. The authors would like to thank Dr. GL Collingridge for very productive discussions during early stages of this work. 


\section{ABBREVIATIONS}

ACSF: $\quad$ artificial cerebrospinal fluid

AHP: $\quad$ after-hyperpolarization

AP-5: $\quad$ D-2-amino-5-phosphonopentanoic acid

EPSC: excitatory postsynaptic current

EPSP: $\quad$ excitatory postsynaptic potential

ISI: $\quad$ inter-spike interval

LFSD: $\quad$ low frequency stimulation coupled with the injection of a continuous

depolarizing current within the postsynaptic CA1 cell

LTP: long-term potentiation

NMDA: $\quad$ N-methyl-D-aspartate

sAHP: $\quad$ slow after-hyperpolarization

SC: $\quad$ Schaffer collateral

$\mathrm{sI}_{\mathrm{AHP}}$ : slow after-hyperpolarization current

TBS: $\quad$ theta burst stimulation

Vr: $\quad$ resting membrane potential 


\section{REFERENCES}

Abraham WC, Bear MF. 1996. Metaplasticity: the plasticity of synaptic plasticity. Trends Neurosci 19:126-130.

Armano S, Rossi P, Taglietti V, D’Angelo, E. 2000. Long-term potentiation of intrinsic excitability at the mossy fiber-granule cell synapse of rat cerebellum. J. Neurosci 20:52085216.

Bekkers JM. 2000. Distribution of slow sAHP channels on hippocampal CA1 pyramidal neurons. J Neurophysiol 83:1756-1759.

Bliss TV, Collingridge GL. 1993. A synaptic model of memory: Long-term potentiation in the hippocampus. Nature 361:31-39.

Bliss TV, Lomo T. 1973. Long-lasting potentiation of synaptic transmission in the dentate area of the anaesthetized rabbit following stimulation of the perforant path. J Physiol (Lond) 232: 331-356.

Borde M, Cazalets JR, Buño W. 1995. Activity-dependent response depression in rat hippocampal CA1 pyramidal neurons in vitro. J Neurophysiol 74:1714-1729.

Borde M, Bonansco C, Buño W. 1999. The activity-dependent potentiation of the slow $\mathrm{Ca}^{2+}$ activated $\mathrm{K}^{+}$current regulates synaptic efficacy in rat CA1 pyramidal neurons. Pflügers Arch 437:261-266.

Borde M, Bonansco C, Fernández de Sevilla D, Le Ray D, Buño W. 2000. Voltage-clamp analysis of the potentiation of the slow $\mathrm{Ca}^{2+}$-activated $\mathrm{K}^{+}$current in hippocampal pyramidal neurons. Hippocampus 437:261-266.

Bortolotto ZA, Collingridge GL. 2000. A role for protein kinase C in a form of metaplasticity that regulates the induction of long-term potentiation at CA1 synapses of the adult rat hippocampus. Eur J Neurosci 12:4055-4062.

Carnevale NT, Hines ML. 1997. The NEURON simulation environment. Neural Comp 9:11791209. 
Carrer H, Araque A, Buño W. 2003. Estradiol regulates the slow $\mathrm{Ca}^{2+}$-activated $\mathrm{K}^{+}$current in hippocampal pyramidal neurons. J Neurosci 23:6338-6344.

Cavus I, Teyler T. 1996. Two forms of long-term potentiation in area CA1 activate different signal transduction cascades. J Neurophysiol. 76:3038-3047.

Chapman CA, Perez Y, Lacaille JC. 1998. Effects of GABA(A) inhibition on the expression of long-term potentiation in CA1 pyramidal cells are dependent on tetanization parameters. Hippocampus 8:289-298.

Chevaleyre V, Castillo PE. 2003. Heterosynaptic LTD of hippocampal GABAergic synapses: a novel role of endocannabinoids in regulating excitability. Neuron 38:461-472.

Cohen AS, Coussens CM, Raymond CR, Abraham WC. 1999. Long-lasting increase in cellular excitability associated with the priming of LTP induction in rat hippocampus. J Neurophysiol 82:3139-3148.

Coulter DA, LoTurco JJ, Kubota M, Disterhoft JF, Moore JW, Alkon DL. 1989. Classical conditioning reduces amplitude and duration of calcium-dependent afterhyperpolarization in rabbit hippocampal pyramidal cells. J Neurophysiol 61:971-981.

Daoudal G, Debanne D. 2003. Long-Term Plasticity of Intrinsic Excitability: Learning Rules and Mechanisms. Learn Mem 10:456-465

Daoudal G, Hanada Y, Debanne D. 2002. Bidirectional plasticity of excitatory postsynaptic potential (EPSP)-spike coupling in CA1 hippocampal pyramidal neurons. Proc Natl Acad Sci USA. 99:14512-14517.

Disterhoft JF, Thompson LT, Moyer JR, Mogul DJ. 1996. Calcium-dependent afterhyperpolarization and learning in young and aging hippocampus. Life Sci 59:413-420.

Eakin TJ, Antonelli MC, Malchiodi EL, Baskin DG, Stahl WL. 1995. Localization of the plasma membrane $\mathrm{Ca}(2+)$-ATPase isoform PMCA3 in rat cerebellum, choroid plexus and hippocampus. Mol Brain Res 29:71-80. 
Egorov AV, Hamam BN, Fransén E, Hasselmo ME, Alonso AA. 2002. Graded persistent activity in entorhinal cortex neurons. Nature 420:173-178.

Fernández de Sevilla D, Cabezas C, Ochima de Prada AN, Sáchez-Jimenez A, Buño W. 2002. Selective muscarinic regulation of functional glutamatergic Schaffer collateral synapses in rat CA1 pyramidal neurons. J Physiol (Lond) 545:51-63.

Fernández de Sevilla D, Buño W. 2003. Presynaptic inhibition of Schaffer collateral synapses by stimulation of hippocampal cholinergic afferent fibres. Eur J Neurosci 17:555-558.

Goussakov IV, Fink K, Elger CE, Beck H. 2000. Metaplasticity of mossy fiber synaptic transmission involves altered release probability. J Neurosci 20:3434-3441.

Grover LM, Teyler TJ. 1990. Two components of long-term potentiation induced by different patterns of afferent activation. Nature. 347:477-479.

Hanse E, Gustafsson B. 1995. Long-term potentiation in hippocampal CA1 region in the presence of $N$-methyl- $D$-aspartate receptor antagonists. Neuorsci 67:531-539.

Hasselmo ME, Barkai E. 1995 Cholinergic modulation of activity-dependent synaptic plasticity in the piriform cortex and associative memory function in a network biophysical simulation. $\mathrm{J}$ Neurosci 15:6592-604.

Hebb DO. 1949. Organization of behavior. New York: Wiley.

Hines ML. 1994. The NEURON simulation program. In: Neural Network Simulation Environments (Skrzypek J, ed.), pp. 147-163. Norwell, MA: Kluwer.

Hodgkin AC, Huxley AF. 1952. A quantitative description of membrane currents and its application to excitation and conduction in nerve. J Physiol (Lond) 117:500-544.

Hoffman DA, Magee JC, Colbert CM, Johnston D. 1997. K+ channel regulation of signal propagation in dendrites of hippocampal pyramidal neurons. Nature 387:869-75.

Hoffman DA, Sprengel R, Sakmann B. 2002. Molecular dissection of hippocampal theta-burst paring potentiation. Proc Natl Acad Sci 99:7740-7745. 
Huang YY, Colino A, Selig DK, Malenka RC. 1992. The influence of prior synaptic activity on the induction of long-term potentiation. Science 255:730-733.

Jacobs JM, Meyer T. 1997. Control of action potential-induced Ca2+ signaling in the soma of hippocampal neurons by Ca2+ release from intracellular stores. J Neurosci 17:4129-4135.

Johnston D, Hoffman DA, Magee JC, Poolos NP, Watanabe S, Colbert CM, Migliore M. 2000. Dendritic potassium channels in hippocampal pyramidal neurons. J Physiol (Lond) 525:7581.

Kaczorowski, CC, Disterhoft JF, Spruston N. 2003. Differential activity-dependent plasticity of the slow afterhyperpolarization evoked by tetanic vs. theta-burst stimulation in CA1 pyramidal neurons: a role for the hyperpolrization-activated cation conductance. Soc Neurosci Program, Abstract No. 369.13.

Lancaster B, Hu H, Ramakers GMJ, Storm JF. 2001. Interaction between synaptic excitation and slow afterhyperpolarization current in rat hippocampal pyramidal cells. J Physiol (Lond) 536:809-823.

Levitan IB. 1994. Modulation of ion channels by protein phosphorylation and dephosphorylation. Annu Rev Physiol 56:193-212.

Linden DJ. 1999. The return of the spike: postsynaptic action potentials and the induction of LTP and LTD. Neuron 22:661-666.

Magee JC, Carruth M. 1999. Dendritic voltage-gated ion channels regulate the action potential firing mode of hippocampal CA1 pyramidal neurons. J Neurophysiol 82:1895-901.

Magee J, Hoffman D, Colbert C, Johnston D. 1998. Electrical and calcium signaling in dendrites of hippocampal pyramidal neurons. Annu Rev Physiol 60:327-346.

Magee J, Johnston D. 1997. A synaptically controlled, associative signal for hebbian plasticity in hippocampal neurons. Science 275:209-213. 
Mainen ZF, Carnevale NT, Zador AM, Claiborne BJ, Brown TH. 1996. Electrotonic architecture of hippocampal CA1 pyramidal neurons based on three-dimensional reconstructions. J Neurophysiol 76:1904-1923.

Markram H, Lubke J, Frotscher M, Sakmann B. 1997. Regulation of synaptic efficacy by coincidence of postsynaptic APs and EPSPs. Science. 275:213-215.

Martin ED, Araque A, Buño W. 2001. Synaptic regulation of the slow Ca2+-activated K+ current in hippocampal CA1 pyramidal neurons: implication in epileptogenesis. J Neurophysiol 86:2878-2886.

Meredith RM, Floyer A, Paulsen O. 2002. Developmental profile of pairing-induced synaptic plasticity in CA1 hippocampus. Soc Neurosci Program, Abstract No. 152.20.

Oh MM, Kuo AG, Wu WW, Sametsky EA, Disterhoft JF. 2003 Watermaze learning enhances excitability of CA1 pyramidal neurons. J Neurophysiol. 90:2171-2179.

Otmakhov N, Griffith LC, Lisman JE. 1997. Postsynaptic inhibitors of calcium/calmodulindependent protein kinase type II block induction but not maintenance of paring-induced long-term potentiation. J Neurosci 17:5357-5365.

Pedarzani P, Krause M, Haung T, Storm JF, Stuhmer W. 1998. Modulation of the Ca2+-activated $\mathrm{K}+$ current sIAHP by a phosphatase-kinase balance under basal conditions in rat CA1 pyramidal neurons. J Neurophysiol 79:3252-3256.

Pedarzani P, Mosbacher J, Rivard A, Cingolani LA, Oliver D, Stocker M, Adelman JP, Fakler B. 2001. Control of electrical activity in central neurons by modulating the gating of small conductance $\mathrm{Ca}^{2+}$-activated $\mathrm{K}^{+}$channels. J Biol Chem 276:9762-9769.

Pike FG, Meredith RM, Oldingand AWA, Paulsen O. 1999. Postsynaptic bursting is essential for 'Hebbian' induction of associative long-term potentiation at excitatory synapses in rat hippocampus. J Physiol (Lond) 518:571-576.

Regehr WG, Tank DW. 1992. Calcium concentration dynamics produced by synaptic activation of CA1 hippocampal pyramidal cells. J Neurosci 12:4202-4223. 
Saar D, Grossman Y, Barkai E. 1998. Reduced after-hyperpolarization in rat piriform cortex pyramidal neurons is associated with increased learning capability during operandconditioning. Eur J Neurosci 10:1518-1523.

Sah P, Bekkers JM. 1996. Apical dendritic location of slow afterhyperpolarization current in hippocampal pyramidal neurons: implications for the integration of long-term potentiation. $\mathrm{J}$ Neurosci 16:4537-4542.

Sah P, Isaacson JS. 1995. Channels underlying the slow afterhyperpolarization in hippocampal pyramidal neurons: neurotransmitters modulate the open probability. Neuron 15:435-441.

Schwartzkroin PA. 1975. Characteristics of CA1 neurons recorded intracellularly in the hippocampal in vitro slice preparation. Brain Res 85:423-36.

Shah MM, Haylett DG. $2002 \mathrm{~K}+$ currents generated by NMDA receptor activation in rat hippocampal pyramidal neurons. J Neurophysiol. 87:2983-2989.

Storm JF. 1990. Potassium currents in hippocampal pyramidal cells. Prog Brain Res 83:161-187.

Tanabe O, Gahwiler BH, Gerber U. 1998. L-type Ca+ channels mediate the slow Ca2+-dependent afterhyperpolarization in rat CA3 pyramidal neurons in vitro. J Neurophysiol 80:2268-2273.

Tokuda M, Hatase O. 1998. Regulation of neuronal plasticity in the central nervous system by phosphorylation and dephosphorylation. Mol Neurobiol 17:137-156.

Tompa P, Friedrich P. 1998. Synaptic metaplasticity and the local effect in postsynaptic densities. Trends Neurosci 21:97-102.

Tsubokawa H, Ross WN. 1997. Muscarinic modulation of spike backpropagation in the apical dendrites of hippocampal CA1 pyramidal neurons. J Neurosci 17:5782-5791.

Vogt K, Streit J, Dityatev A, Luscher HR. 1997. Synaptic plasticity in dissociated hippocampal cultures: pre- and postsynaptic contributions. Eur J Neurosci. 9:1078-82. 
Wang Z, Xu N, Wu C, Duan S, Poo M. 2003. Bidirectional changes in spatial dendritic integration accompanying long-term synaptic modifications. Neuron 37:463-472.

Wu WW, Oh MM, Disterhoft JF. 2002. Age-related biophysical alterations of hippocampal pyramidal neurons: implications for learning and memory. Ageing Res Rev 1:181-207.

Yamada WM, Koch C, Adams PR. 1989. Multiple channels and calcium dynamics. In: Methods in neuronal modeling (Koch C, Segev I, eds.), pp. 97-133. Cambridge, MA: MIT press.

Yasuda R, Sabatini BL, Svoboda K. 2003. Plasticity of calcium channels in dendritic spines. Nat Neurosci 6:948-955.

Zhang W, Linden DJ. 2003. The other side of the engram: experience-driven changes in neuronal intrinsic excitability. Nature Neurosci 4:885-900.

Zhang L, Weiner JL, Valiante TA, Velumian AA, Watson PL, Jahromi SS, Schertzer S, Pennefather P, Carlen PL. 1994. Whole-cell recording of the $\mathrm{Ca}^{2+}$-dependent slow afterhyperpolarization in hippocampal neurones: effects of internally applied anions. Pflügers Arch 426:247-253. 


\section{FIGURE LEGENDS}

\section{FIGURE 1: Heterosynaptic metaplasticity at Schaffer collateral-CA1 pyramidal neuron} synapses. A, Diagram of experimental setup showing recording at the soma of a CA1 pyramidal neuron and stimulation of two Schaffer collateral apical dendritic synaptic inputs (SC1 and SC2). B, EPSP peak amplitudes (empty circles) as a function of time in control conditions and following tetanization of a Schaffer collateral input (empty bar, SC1 Tet.), which induced LTP of the SC1-evoked EPSP. Tetanization applied 45 min later to the SC2 afferent pathway (gray bar, SC2 ${ }_{1}$ Tet.) failed to generate LTP (gray circles), but $~ 15$ min later the same SC2 tetanization (black bar, $\mathrm{SC}_{2}$ Tet.) evoked the LTP of the SC2-evoked EPSPs. C, Mean peak amplitudes of the sAHP in the same experiments as in A showing a prolonged potentiation of the sAHP (filled circles), and control recording of the sAHP (empty triangles, without tetanization). In $\mathbf{B}$ and $\mathbf{C}$ same cells, $\mathrm{n}=5$. $\mathbf{D}$, top, Superimposed control (1) and post-tetanization EPSP (2) averages (3 traces each). D, bottom, Same as top but sAHP. E, Summary data showing sAHP (black bars), SC1 EPSPs (empty bars) and SC2 EPSPs (gray bars) amplitudes relative to controls (\%; $n=5)$, immediately after the $S C 2_{1}$ tetanization (SC2 1 Tet.) and 60 min after, when the sAHP had returned close to control values (SC2 2 Tet.).

FIGURE 2: The $\boldsymbol{s I}_{A H P}$ potentiation. A, Time course of peak EPSC (empty circles) and $\mathrm{sI}_{\mathrm{AHP}}$ (filled circles; $n=6$ ) amplitudes, before and after tetanization of a Schaffer collateral input (empty bar, SC Tet.). B, Parallel increase in the decay time constant ( $\tau$; gray circles) and in the peak amplitude (filled circles; $n=11$ ) of the $\mathrm{sI}_{\mathrm{AHP}}$ following potentiation by $\mathrm{SC}$ tetanization (SC Tet.). C, Superimposed averages (3 successive responses each) of the $\mathrm{sI}_{\mathrm{AHP}}$ and EPSCs, illustrating controls and simultaneous LTP and $\mathrm{sI}_{\mathrm{AHP}}$ potentiation induced by pairing a low frequency stimulation with a sustained postsynaptic depolarization to $0 \mathrm{mV}$ (LFSD). D, Same as C, but using a theta-burst stimulation (TBS) induction protocol. 
FIGURE 3: Excitability and firing depression during the sAHP potentiation. A, representative record illustrating the spike activity evoked by sustained depolarizing current and by a current pulse (i) added at specified times. The pulse was of lower intensity (0.1-0.5 nA, $200 \mathrm{~ms}$ ) than that used to evoke a large sAHP in the previous experiments. The inter-spike intervals (arrowheads) were longer after the pulse due to the activation of the sAHP. B, Plot of inter-spike interval (ISI) -between spikes following the pulse- versus time, under stimulations as in A obtained 8 and 2 min before and up to 34 min after SC tetanization. Arrows indicate successive depolarizing pulses and empty bar the SC tetanization (SC Tet.). Note the longer delay (d) to the first spikes following the burst evoked by the current pulses and the longer subsequent ISI following the SC tetanization, indicating a depression of excitability due to the potentiated sAHP. C, Summary data illustrating the sAHP peak amplitude (\% of controls; black bars) and the number of spikes (gray bars) following pulse-evoked bursts (spikes were counted during $2 \mathrm{~s}$ after bursts). Group 1: 15 min after SC tetanization when the sAHP was potentiated ( $\mathrm{n}=12)$; Group 2 (control): in the absence of sAHP potentiation 35 min after impaling the cell $(n=4)$. Note in group 1 the potentiated sAHP (black bars) and the parallel reduction of CA1 firing (gray bars) and in group 2 the lack of sAHP and spike changes. D, Summary data showing the changes in the mean delay (d) as a function of time before (control) and following (up to >30 min) the conditioning SC tetanization $(n=8)$.

\section{FIGURE 4: The sAHP potentiation strongly depresses postsynaptic excitability. A, upper} representative records showing fully potentiated sAHP 30 min post-SC1 tetanization and its gradual recovery to control values $50 \mathrm{~min}$ and $100 \mathrm{~min}$ post SC1 tetanization. A, lower, responses evoked by single $200 \mathrm{~ms} / 70 \mathrm{~Hz}$ barrage applied to the non-potentiated SC2 afferent at the same time points as upper. Note the progressive improvement of the spike response (i.e., of the excitability) as the sAHP gradually recovered control values. B, Relationship between the sAHP peak amplitude (following its potentiation) and the mean 
spike frequency of bursts (\% of controls) generated by single $200 \mathrm{~ms} / 70 \mathrm{~Hz}$ barrages applied to the SC2 input (dashed line: linear fit, $r=0.84$ ). Out of range values were probably due to involvement of unrelated ionic conductances. C, Representative example of control and potentiated sAHP 10, 20 min after the SC1 tetanization (Post-tet., horizontal bar), and partial recovery after $50 \mathrm{~min}$. D, As above but responses evoked by a $200 \mathrm{~ms} / 50 \mathrm{~Hz}$ barrage applied at the SC1 input before tetanization (Control) and responses evoked by $200 \mathrm{~ms} / 50$ and $200 \mathrm{~Hz}$ barrages applied at the SC2 input, 10 and 20 min after tetanization (Post-tet., horizontal bar), both when the sAHP was potentiated. The $200 \mathrm{~ms} / 50 \mathrm{~Hz}$ barrage presented at the SC2 input 50 min after, when the sAHP had recovered control values is also shown. Note smaller depolarization following the initial spikes 10 and 20 min after the SC1 tetanus, and the larger depolarization and spike firing of the final SC2 responses that is similar to the control SC1 response. $\mathbf{C}$ and $\mathbf{D}$, same cell.

FIGURE 5: Contribution of NMDA and L-type $\mathrm{Ca}^{2+}$ conductances. A, upper records, representative example of SC1 EPSPs in control solution and under $20 \mu \mathrm{M}$ nimodipine (horizontal bar) before and after (30 min) tetanization of SC1 afferents (Pre-tet. and Post-tet., respectively). A, lower records, same as upper but showing the sAHP (upper and lower records, same neuron). B, Summary data $(n=6)$ illustrating peak amplitude changes (\% of controls) of sAHP and SC1 EPSP in control condition (empty bars) and 20 min after tetanization of the SC1 input (black bars) under nimodipine (20 $\mu \mathrm{M}) . \mathbf{C}$ and $\mathbf{D}$, as in A and B, but showing the effects of $50 \mu \mathrm{M} \mathrm{AP}-5(n=6)$.

FIGURE 6: Simulation: the potentiated ${ } I_{A H P}$ mediates heterosynaptic metaplasticity. A and $\mathbf{B}$, The potentiation of both the $\mathrm{sI}_{\mathrm{AHP}}$ peak amplitude and decay time constant were simulated by decreasing the velocity of $\mathrm{Ca}^{2+}$ capture by internal buffers (A) and increasing the time constant of sI $\mathrm{AHP}_{\mathrm{AP}}$ channel closure $(\mathbf{B})$, respectively. Both plastic processes were initiated by the occurrence of ten consecutive pre- and postsynaptic spikes (at a minimum instantaneous frequency of $40 \mathrm{~Hz}$; see Methods) and incremented for every new spike fulfilling the $40 \mathrm{~Hz}$ 
pre-postsynaptic spike condition. $\mathbf{C}$ and $\mathbf{D}$, Simulation of the sAHP-dependent heterosynaptic metaplasticity at CA3-CA1 synapses. The first $40 \mathrm{~Hz}$ tetanization applied to the SC1 input (C, $\mathrm{SC1}_{1}$, empty bar) generated sufficient postsynaptic firing (D, left) to induce the homosynaptic LTP and potentiate the sAHP (not illustrated), but did not modify SC2-evoked EPSPs. A subsequent $40 \mathrm{~Hz}$ tetanization of the non-potentiated SC2 input when the sAHP was maximally potentiated (C, gray bar) did not generate a sufficient firing (D, middle) to meet the criteria for inducing LTP at the SC2 input and to potentiate the sAHP. In contrast, the tetanization of the potentiated SC1 input was still able to generate sufficient spikes to meet the criteria for LTP even though the sAHP remained potentiated $\left(\mathbf{C}, \mathrm{SC}_{2}\right.$, empty bar; and $\mathbf{D}$, right). 

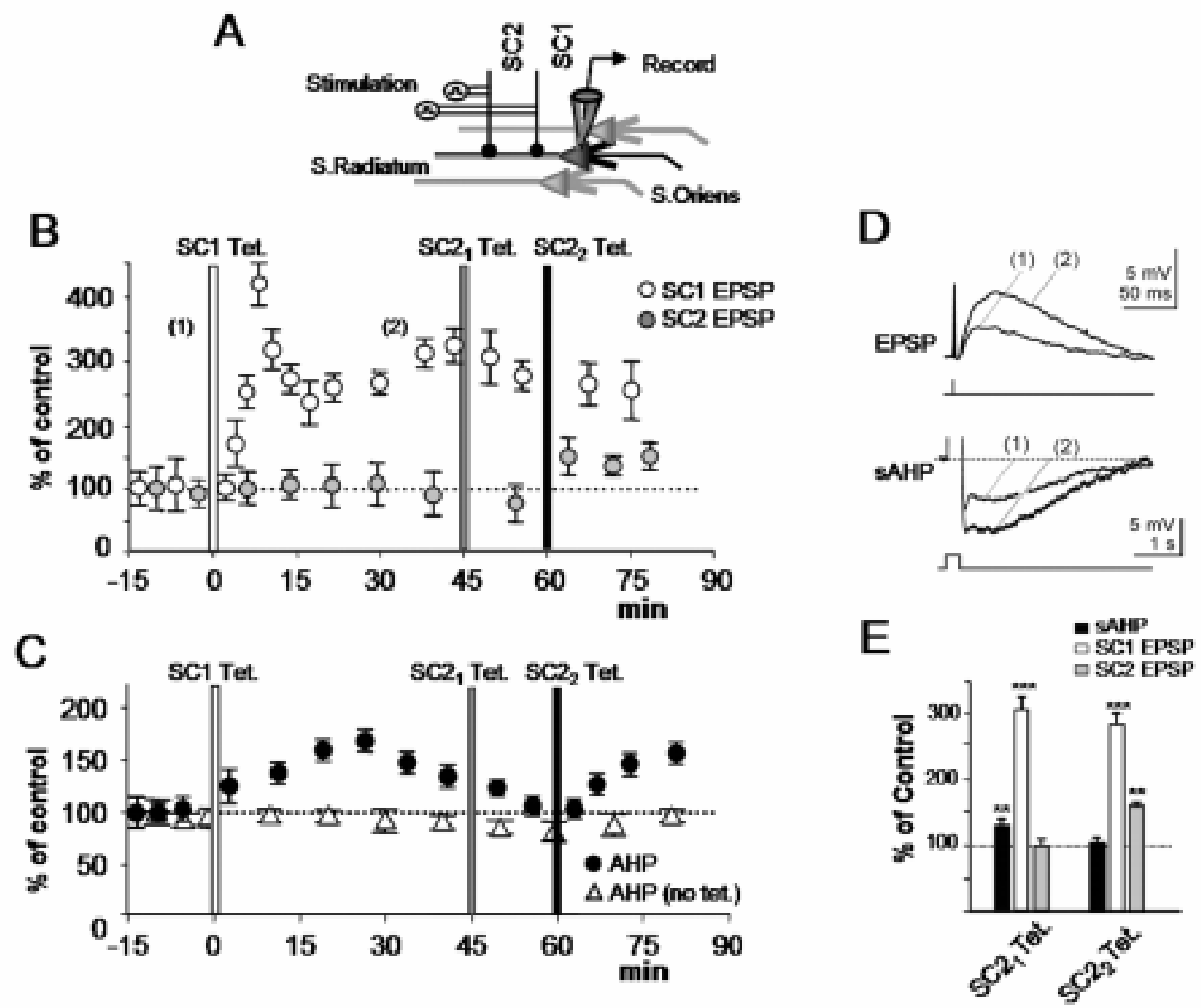

Fig. 1 

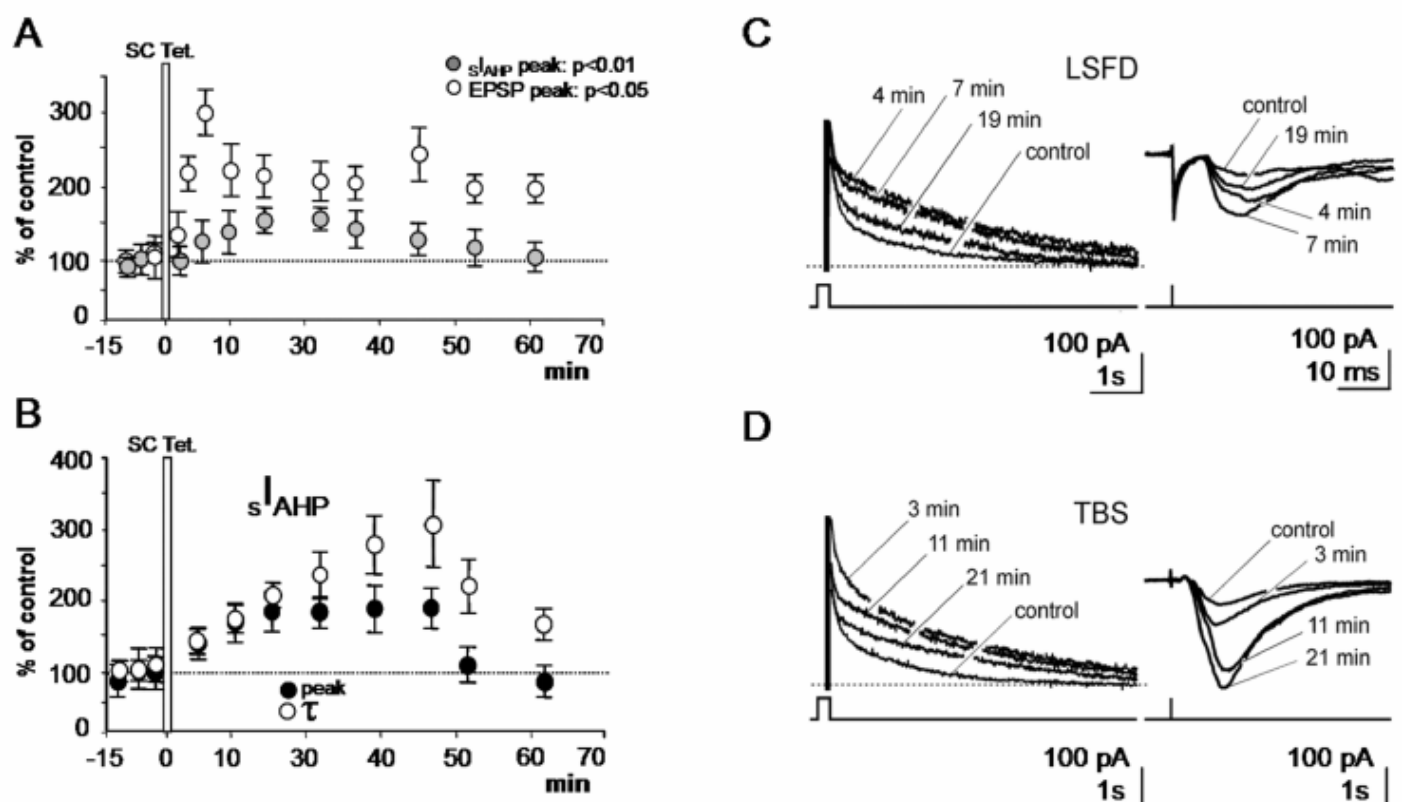

D

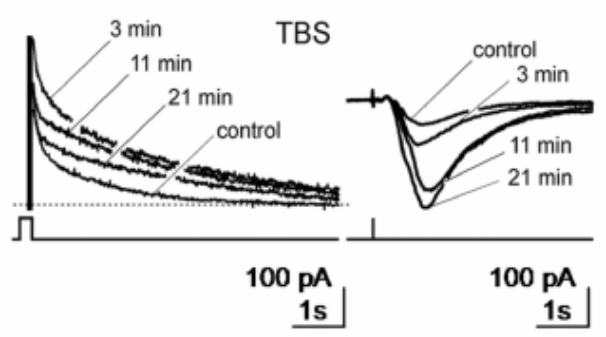

Fig. 2 


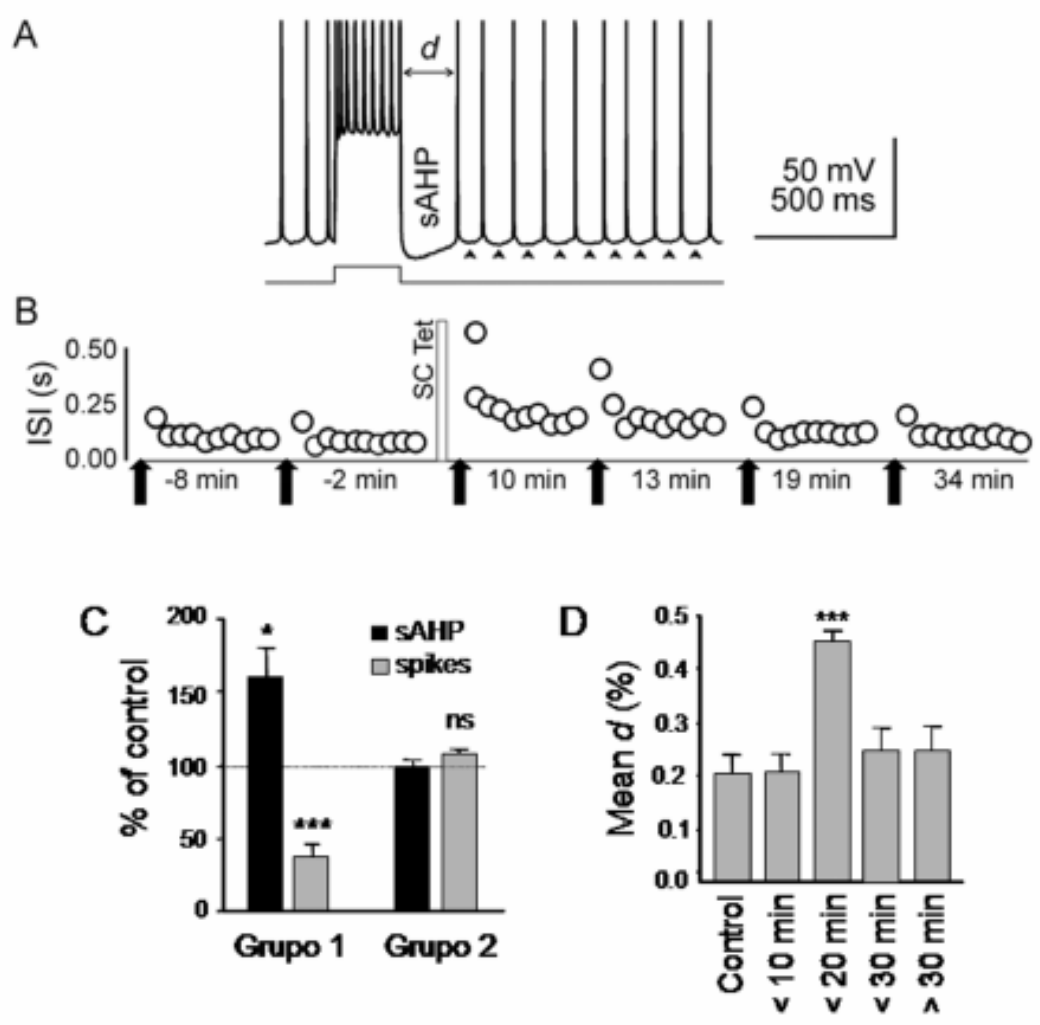

Fig. 3 
A

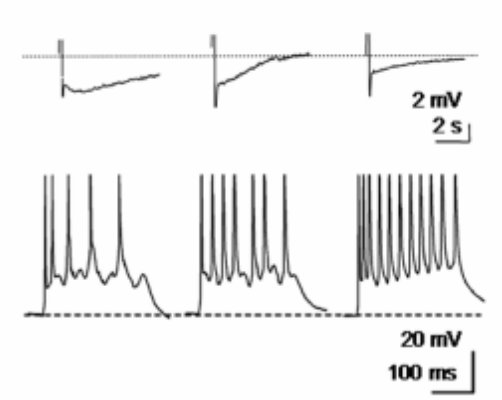

C

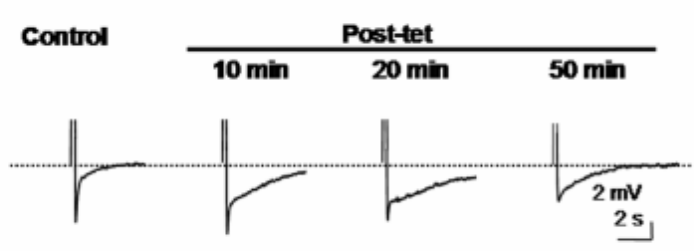

D Control

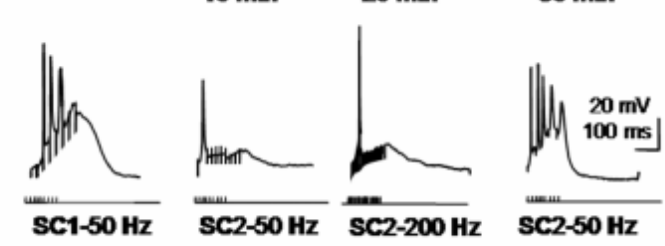

B

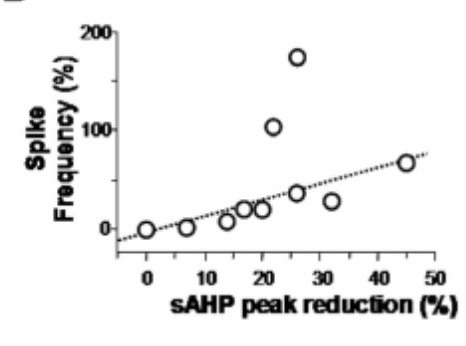

$\mathrm{E}$

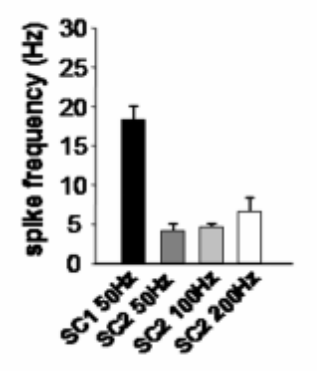

$\mathrm{F}$

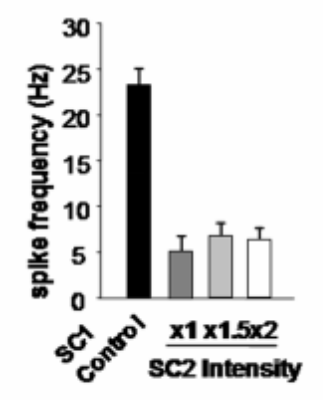

Fig. 4 
A

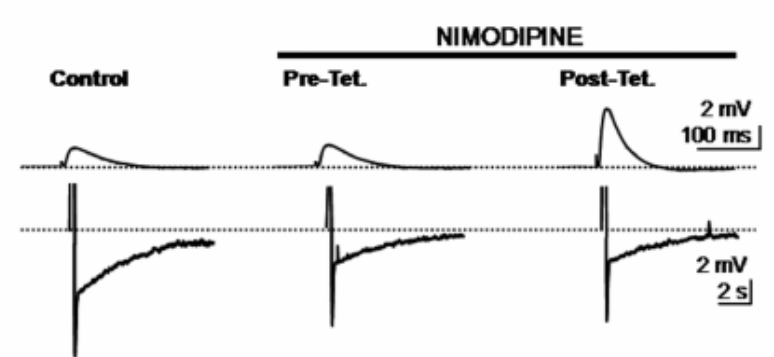

C

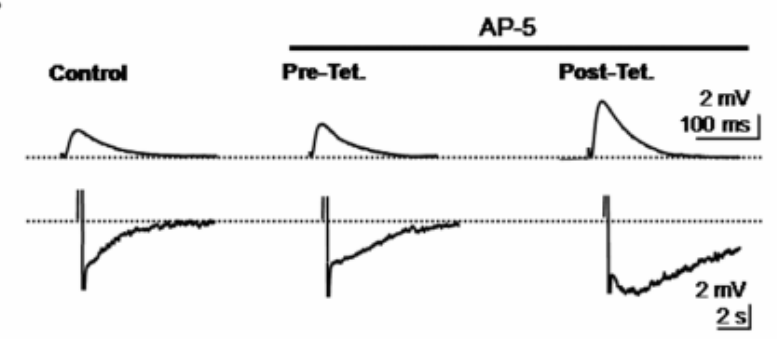

B

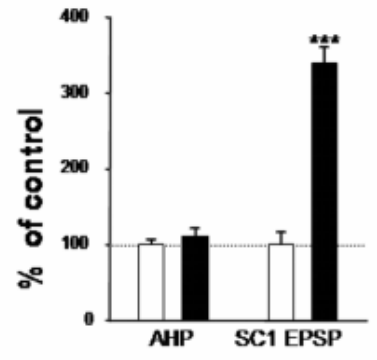

D

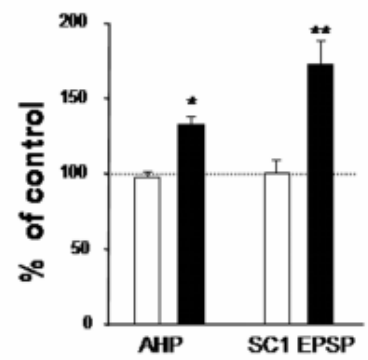

Fig. 5 
A
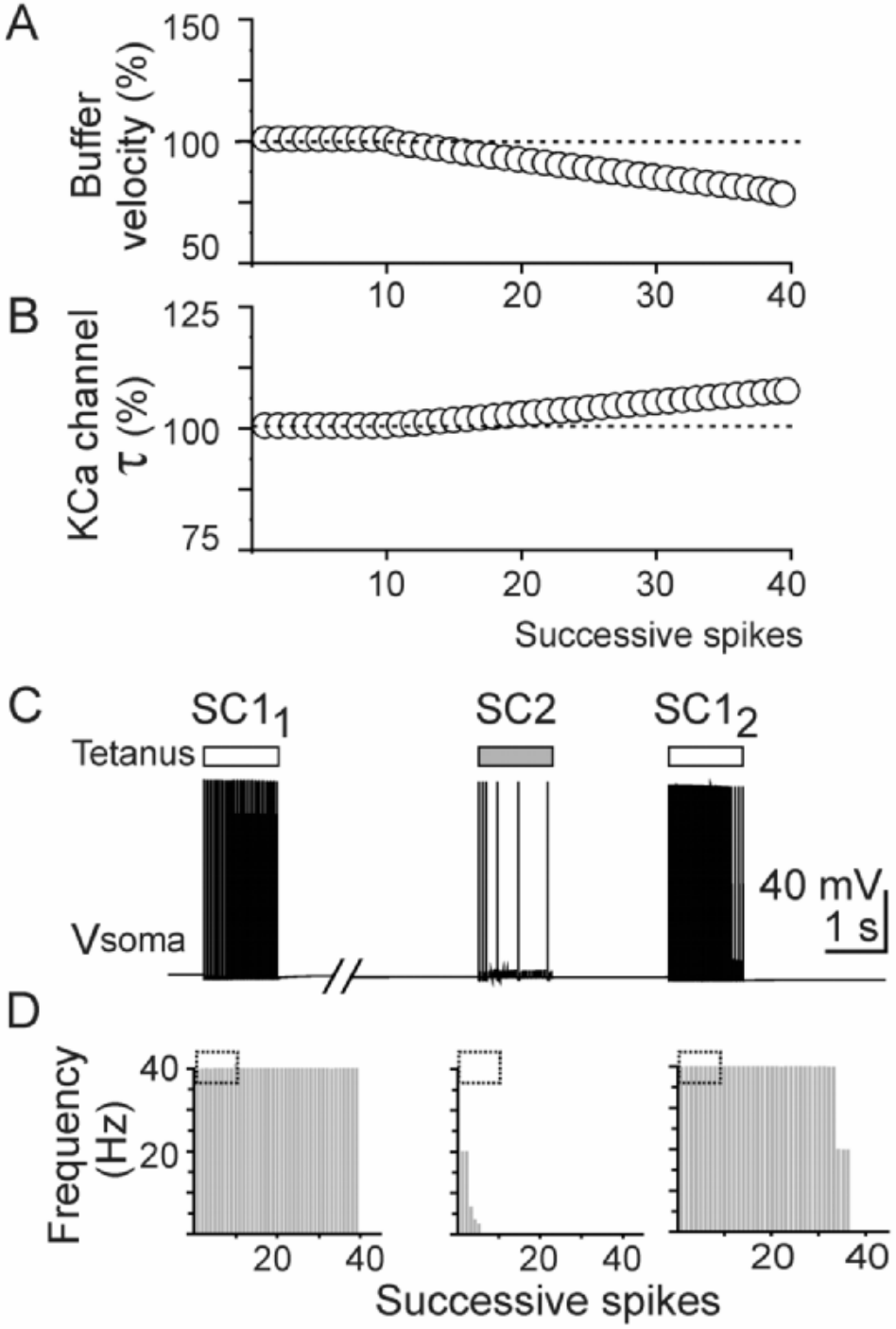

Fig. 6 